Published in Social Sciences 10 (9): 347. DOI: 10.3390/socsci10090347

\title{
Can Regional Gender Ideologies Account for Variation of Gender Pay Gaps? The Case of Germany
}

\author{
Maik Hamjediers \\ Humboldt-Universität zu Berlin, Department of Social Sciences
}

\begin{abstract}
While research often invokes gender disparities in wage-determining characteristics to explain gender pay gaps, why these gender disparities and gender pay gaps vary across contexts has received less attention. Therefore, I analyze how subnational gender ideologies predict gender pay gaps in two ways: as directly affecting gender pay gaps and as indirectly predicting gender pay gaps through intermediate gender disparities in determinants of wage. The analyses are based on German survey data (SOEP 2014-2018) supplemented with regional-level statistics. First, I leverage regional differences in predictors of gender ideologies to estimate region-specific gender ideologies. Mapping these gender ideologies across Germany reveals substantial regional variation. Second, multilevel models provide region-specific gender disparities in wage determinants and gender pay gaps. Results reveal that traditional gender ideologies are associated with women gaining less labor market experience and working less often in full-time jobs or supervising positions. In addition to this indirect association, gender ideologies directly predict the extent of adjusted gender pay gaps. These associations contribute novel evidence on regional variation of gender ideologies and how they can underlie explanations often invoked for gender pay gaps.
\end{abstract}

Keywords: gender pay gap; gender ideologies; regional variation; small area estimation; multilevel models 


\section{Introduction}

On average, women earn less than men, and this gender pay gap has been quite stable in recent decades (Finke et al., 2017; Blau and Kahn, 2017). While men's historical advantage in educational attainment vanished (Quenzel and Hurrelmann, 2010), greater domestic responsibilities for women - especially in childbearing and -rearing - are currently more relevant for the emergence of gender pay gaps (Kleven et al., 2019). They limit women's labor force engagement and interrupt their employment trajectories, and women are more likely to hold jobs allowing time-flexibility to resolve family-work conflicts (Goldin, 2014). These lower human capital endowments for women are one reason for the emergence of gender pay gaps. Additionally, as part-time jobs and timeflexible jobs come with the costs of providing less opportunities for career progression, fewer women reach managerial positions (Holst and Wrohlich, 2018). This vertical occupational segregation (Charles, 2003) is accompanied by horizontal segregation of work-family considerations, divergent interests, and occupational gender stereotypes sorting women and men into different branches of industries and occupations (Busch, 2013b; Levanon and Grusky, 2016). A devaluation of occupations in which women outnumber men underline the gender pay gaps as well (England, 1992; Busch, 2013a). However, even when both genders have equal human capital and work in identical occupational positions, a gender pay gap persists. Hence other factors, such as discrimination against women and differences in wage-negotiation behavior, have been invoked to explain the remaining part (e.g., Azmat and Petrongolo, 2014; see also Blau and Kahn, 2017 for a comprehensive overview).

However, gender pay gaps are not equal across all contexts. While the varying extent to which men out-earn women across countries has been well described (Fortin, 2005; Blau and Kahn, 2017), the variation in gender pay gaps within countries receives less attention. This study therefore analyzes regional variation of gender pay gaps for the case of Germany. Germany's Federal Statistical Office reports a national raw gender pay gap of 21 percent for 2018 (Federal Statistical Office, 2019), which is a comparatively large gap for Europe (Boll et al., 2017). While employment rates for women and men have considerably converged, 47 percent of women work part-time and only 9 percent of men do so (Federal Statistical Office, 2019). A gendered allocation of employment and child care is partly incentivized by Germany's policies (e.g., joint taxation of married couples and dependent coverage of non-working partners in health insurance plans; Trappe et al., 2015) and ideologically supported by around half of the population holding essentialist and traditional gender ideologies (Grunow et al., 2018). While such policies apply nation-wide, counties differ in their provision of public child-care, which has been considerably expanded since the mid-2000s (Zoch and Schober, 2018). The policies and ideological importance within Germany can be highlighted by disparities between East Germany (former German Democratic Republic) and West Germany, with greater public child care provision and more egalitarian gender ideologies in East Germany prompting smaller gender pay gaps than those in West Germany (Achatz et al., 2005; Minkus and Busch-Heizmann, 2018). Further, research has found that women in rural areas are more disadvantaged than women in urban areas (Hirsch et al., 2013; Nisic, 2017), and using fine-grained administrative counties, Fuchs et al. (2019) reveal most comprehensively that gender pay gaps vary subnationally within Germany. They show that large parts of regional differences in gender pay gaps - and especially the difference between East and West Germany - can be accounted for by the regional dispersion of gender inequalities in wage-determinants. Nevertheless, even after adjusting for structural factors, variation in the gender pay gap across counties is left to be explained.

To account for such subnational variations in gender pay gaps, this study draws on regional employment-related gender ideologies. These are shared expectations about the gendered division of labor, such as traditional beliefs of men ought to be the main breadwinner and women primary caregivers or a belief in an incompatibility of motherhood and paid work (Davis and Greenstein, 2009). As they do not only address wages, but labor market behavior more generally, they provide a normative ground for why not only regional gender pay gaps can be accounted by them, but also why gender inequalities in wage-determinants, such as inequalities in human capital endowment and occupational choices, emerge and vary within countries. Thus, the association of gender ideologies and gender pay gaps can be partitioned into indirect associations running through gender inequalities in intermediate wage-determinants and rather direct associations of gender ideologies and adjusted gender pay gaps. Using large-scale survey data from the German Socio-Economic 
Panel from 2014 to 2018 and regional level auxiliary information of the German Federal Statistical Office, I show how gender ideologies vary across German labor market regions and examine their association with gender inequalities in wage-determinants and (adjusted) gender pay gaps.

This study makes two contributions. First, gender ideologies as a predictor for gender differences have been predominantly examined in cross-national comparisons. However, nations differ on a whole list of socio-political and institutional factors causing national idiosyncrasies to potentially confound results. On a subnational level, studies of Germany highlight more egalitarian attitudes in the former GDR in comparison to West Germany (Lee et al., 2007; Zoch, 2021). The extent of further regional heterogeneity remains an open question. In response, I analyze German labor market regions, which provide larger statistical power than cross-national studies of few countries, avoid confounding due to national idiosyncrasies, and contribute novel evidence of how gender ideologies account for gender pay gaps within Germany. Second, examining not only gender pay gaps but also gender inequalities in wage-determinants sheds light on how gender ideologies directly and indirectly affect gender pay gaps. On the one hand, this emphasizes that gender inequalities in, for instance, labor market experience, working hours, or occupational choices, do not necessarily explain gender pay gaps; rather, they need to be explained as well (Lips, 2013), and regional gender ideologies are highlighted as one of their potential causes. On the other hand, a direct association between gender ideologies and pay gaps endorses concerns that cultural contexts likely maintain gender pay gaps via discrimination or gender-specific wage-negotiation behavior even when policies aiming at equipping women and men with equal labor market endowments would succeed (Aisenbrey and Brückner, 2008).

\section{The Importance of Regional Gender Ideologies}

"Gender ideologies are sets of widely taken-for-granted cultural beliefs about the essential natures and relative worth of men and women." (Chatillon et al., 2018, p. 217). Regarding employment, traditional gender ideologies encompass expectations about a gendered division of labor in which men occupy the role of main breadwinners and women occupy the role of primary caregivers, often associated with the belief of an incompatibility of motherhood and paid work (Davis and Greenstein, 2009). Cross-national variation in gender ideologies has been shown to be predictive of a broad range of social phenomena, such as the allocation of work within households (Fuwa, 2004), the labor force attachment of women (Fortin, 2005) and fertility behavior (Arpino et al., 2015). However, gender ideologies vary not only across countries, but also within countries, such as across states (Pessin, 2018), smaller governmental units (Uunk and Lersch, 2019), or commuting zones (Scarborough and Sin, 2020).

Subnational variation in gender ideologies is driven by the composition of the region as well as norm persistence (Scarborough and Sin, 2020). Regional gender ideologies can be inferred from the average of individually held beliefs (Horne and Mollborn, 2020) and thereby depend on the composition of the region's members. Thus, they are affected by on the one hand immigration from more traditional contexts (Fernández, 2007; Polavieja, 2015) or Christian religious dominations promoting strong gender stereotypes (Bozzano, 2017), and on the other hand by women-especially working women - adopting progressive gender beliefs as those promise them better opportunities in the labor market (Bolzendahl and Myers, 2004), educational institutions transmitting liberal beliefs related to women's economic opportunities (Bolzendahl and Myers, 2004; Lee et al., 2007), or cohort replacement with younger birth cohorts holding less restrictive attitudes about mother's employment (Brooks and Bolzendahl, 2004; Perales et al., 2019). Additionally, historical circumstances, such as agricultural technologies or heritage arrangements, are linked to specific gender arrangements and once developed, corresponding regional gender ideologies persist independently from compositional effects (Giuliano, 2018). Heterogeneity of behavior, for instance in densely populated urban contexts, can nevertheless counteract a persistence of traditional beliefs (Bolzendahl and Myers, 2004).

Varying compositions and norm persistence across regions result in region-specific gender ideologies. They in return impact behavior of members of each region by providing a set of collective expectations of how to adequately present oneself and interact (Horne and Mollborn, 2020). These expectations can be internalized by inferring them from observing gendered behavior of others (Gilbert, 1998). For instance, observing few men engaging in housework leads to the expectation 
that this is not appropriate for them (Evans, 2016), or being exposed to higher female employment rates can "dispel myths about women's capabilities to perform in the workplace" (Bolzendahl and Myers, 2004, p. 762). Similarly, judging behavior in conversations among neighbors, family members, co-workers, and acquaintances transmits expectations about what men and women ought to do (Davis and Greenstein, 2009). Thereby, a tendency that individual-level beliefs align with contextual gender ideologies emerges, and individuals try to act in accordance with the internalized expectations to avoid cognitive dissonance (Cooper and Croyle, 1984) and to perform their gender identity (West and Zimmerman, 1987).

As this alignment is only probabilistic, individuals may still deviate in their beliefs (Polavieja, 2015). However, regional gender ideologies induce gendered outcomes even when these are not personally endorsed. Empirical research indicates that individuals orient their behavior towards perceived gender ideologies irrespective of their own beliefs due to fear of social disapproval (Thébaud and Pedulla, 2016; Salikutluk and Heyne, 2017). Additionally, others' behavior in accordance with regional gender ideologies leads to differential treatment of men and women. If employers or clients disapprove of women's labor force participation, their beliefs could result in using an applicant's gender to refrain from hiring women or avoidance to interact with female employees, respectively, (Taylor et al., 2019). Finally, regional gender ideologies are also institutionalized, for instance, in a lack of public childcare provision, which predominantly constrains women's employment (Chung and Meuleman, 2017). Thus, regional gender ideologies affect behavior by their transmission into individually held beliefs, but moreover also by incentivizing and constraining behavior that is in accordance with them.

The fact that regional gender ideologies do not merely depend on the composition of individually held beliefs but also persist in regional institutions and shape beliefs of the members of a region results in an interdependence of the regional-level gender ideologies, the region's institutions, and individually held beliefs (Scarborough and Risman, 2017). Changes at one level, such as an increase in public childcare provision, subsequently affect the other levels, such as individual beliefs and collective acceptance (Zoch and Schober, 2018). However, research indicates that the aggregate ideologies are highly persistent and change rather slowly (Giuliano, 2018). This is most prominently illustrated for Germany by the comparison of East and West Germany. The institutions and a cultural narrative of gender equality induced liberal gender beliefs to the population of the GDR in the East, while an institutionalized male breadwinner model in West Germany promoted traditional gender ideologies (Trappe et al., 2015). Even 30 years after unification, differences endure irrespective of compositional changes and institutional convergences with East Germans being still more supportive of female employment and especially of mother's employment (Zoch, 2021; Lee et al., 2007).

Thus, this study takes regional gender ideologies as its starting point, which are conceptualized as being dependent on a region's composition and history. They are expected to cause gendered outcomes via their internalization as individual-level beliefs, inducing compliance irrespective of individual-level beliefs, differential treatment by others, and institutionalized constraints and incentives.

\section{Gender Ideologies Shaping Gender Pay Gaps}

The gender pay gap is one gendered outcome likely affected by regional gender ideologies. Based on the understanding that traditional gender ideologies involve expectations of women's primary care giver role and a disapproval of employment for mothers, the above outline leads to the following expectation: A region's traditional gender ideology leads to a greater gender pay gap within that region (H1). However, as gender ideologies involve not only expectations about wage earning, but of gendered behavior more generally, they provide a normative ground for gender inequalities in wage-determinants as well. The link between gender ideologies and gender pay gaps can thereby be differentiated into direct and indirect channels, with the latter capturing how the most relevant structural predictors of gender pay gaps, namely, human capital and occupational segregation, mediate the association of regional gender ideologies and regional gender pay gaps (Figure 1). Moreover, "learning" gender ideologies from observations of gendered behavior and gender inequalities introduces a feedback loop of existing gendered outcomes affecting gender ideologies. Such reversed causality likely leads to an overestimation of the association, yet as 
norms change rather slowly, reversed causality is unlikely to invalidate the association by completely accounting for it. To highlight the importance of gender ideologies causally shaping gender pay gaps, I focus on causal evidence of all above mentioned pathways (internalization, adherence, behavior of others, and institutionalization) in the following review. An empirical assessment is also provided for the internalization and institutional mechanism in supplementary analyses (see Section 5.2) and the issue of potential reversed causality will be discussed in the conclusion.

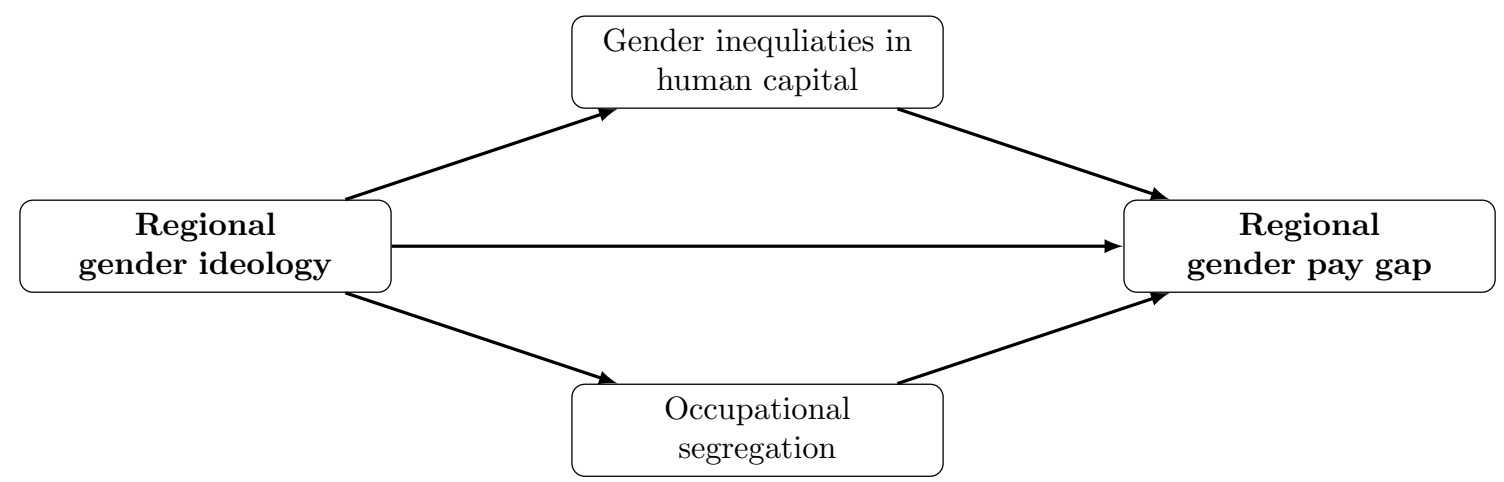

Figure 1: Schematic Depiction of How Gender Ideologies Affect Gender Pay Gaps.

Starting with human capital, research suggests that gender inequalities in working hours and labor market experience depend on contextual gender ideologies (Fortin 2005, 2015). Convincing evidence for a causal effect stems from a discontinuity in the earnings distribution within couples, which can be explained by women decreasing their working hours when otherwise they might deviate from male breadwinner norms by out-earning their husbands (Bertrand et al., 2015; Sprengholz et al., 2020). Care work - especially childbearing and -rearing - is another major reason for women more often working part-time and gaining less labor market experience than men. Steinhauer (2018) provides evidence for contextual ideologies causally shaping mothers' withdrawal from employment by exploiting road distance to the German-French language barrier in Switzerland as exogenous variation in norms. This effect may derive from traditional contexts providing less family-friendly policies (Chung and Meuleman, 2017) or raising women's preference for part time work by normatively assigning care-work to them (Kaufman and White, 2015). Thus, I expect: Traditional regional gender ideologies increase gender inequalities in (H2a) full-time employment and $(\mathrm{H} 2 \mathrm{~b})$ in labor market experience.

Gender pay gaps are also a result of women and men working in different occupational positions, known as occupational segregation. Vertical and horizontal segregation can be distinguished, with the former covering placement across hierarchies and the latter covering sorting into occupations. Charles (2003) indicates that each dimension correlates with contextual gender ideologies, thereby highlighting how segregation itself is conditional on gender ideologies. Regarding vertical segregation, women's implicit self-assessment of their leadership competences responds to experimentally varied exposure to occupational gender roles (Rudman and Phelan, 2010). Women's likelihood of receiving promotions depends also on employer's "perceptions of incongruity between female gender roles and leadership roles" (Eagly and Karau, 2002). Similarly, horizontal segregation can be traced back to individual behavior and treatment by others. For instance, exposing students to beliefs in men's greater ability in a task affected men's own skills assessment and aspirations for occupations requiring respective skills (Correll, 2004). Individual gender beliefs similarly shape the extent that one aspires an occupation that is dominated by one's gender (Judge and Livingston, 2008). However, even when women and men apply for the same job, employers may treat men and women differently based on gender role stereotypes (Rice and Barth, 2017) and due to implicit biases about women's abilities in occupation-specific tasks (Reuben et al., 2014). Therefore, a third hypothesis attributes labor market segregation to regional gender ideologies: Traditional regional gender ideologies increase $(\mathrm{H} 3 \mathrm{a})$ gender inequalities in supervisory positions and $(\mathrm{H} 2 \mathrm{~b})$ greater horizontal segregation.

Even after adjusting for gender inequalities in these wage-determinants, a gender pay gap remains, suggesting a direct channel of gender ideologies towards gender pay gaps. Lalive and Stutzer 
(2010) show that subnational gender ideologies (measured by vote shares in Swiss communities on adding a constitutional equal rights amendment in 1981) are strongly associated with the extent of adjusted gender pay gaps. A potential explanation is that women exposed to traditional gender ideologies are less competitive and negotiate less for wages due to expectations that men ought to earn the main income and that women's primary responsibility lies within the domestic sphere. Lab experiments support this notion by showing that women are less likely to negotiate for higher earnings in a control condition; however, this difference disappears when perceived social desirability of wage negotiations is changed by explicitly stating that wages are negotiable (Leibbrandt and List, 2015). Additionally, discrimination implies that gender ideologies matter not only by altering behavior of wage earners but also by building the foundation of biases against women (Blau et al., 2006, 23). Vignette studies indicate a general norm of lower payment for women in Germany (Auspurg et al., 2017), which holds especially for West Germany and to a lesser extent for East Germany (Lang and Groß, 2020). Finally, gender inequalities in omitted wage-determinants could also account for a remaining adjusted gender pay gap. However, if these are caused by the juxtaposition of gender ideologies evoking gender inequalities, the omission of unobserved wage-determinants does not counteract an expected association of gender ideologies and adjusted gender pay gaps. A fourth hypothesis summarizes: Regions with traditional gender ideologies predict greater gender pay gaps even after accounting for gender inequalities in observed wage-determinants (H4).

\section{Materials and Methods}

To assess the hypotheses, I utilize German labor market regions as contextual units. The German Federal Office for Building and Regional Planning defines 257 distinct labor market regions for Germany. They are based on counties that hand out social security payments, arrange public transport, and conduct communal family politics. While the counties alone have a predominantly administrative purpose, labor market regions are based on merging counties together via commuting patterns across them. Thereby, obtaining the labor market regions of residence captures spaces not only where individuals spend their everyday life, but that are also largely congruent with their workplaces. Bigger regional demarcations, such as federal states, might be culturally more coherent due their historical roots; however, they fall short in capturing the daily work and life settings and yield less statistical power due to fewer observations than labor market regions. Thus, taking labor market regions as the contextual units has been proven to be the most suitable approach (Taylor et al., 2019; Scarborough and Sin, 2020). ${ }^{1}$

The data used for this study consist of five pooled survey waves (2014 to 2018) from the German Socio-Economic Panel (SOEP), an annual representative household survey for the German residential population (Goebel et al., 2019). The analysis is limited to a cross-sectional approach since gender attitudes were only surveyed in 2018. While restricting the estimation sample for the gender pay gaps to the same survey wave of 2018 would have the advantage of limiting potential feedback effects of existing gender inequalities in the labor market shaping gender ideologies, one single wave would provide a much smaller sample size $(N=9013)$, leaving few individuals in some labor market regions. By contrast, I pool the five waves of 2014 to 2018 to account for panel attrition of individuals who did not participate in the survey wave of 2018, which provides bigger sample sizes in each of the 257 labor market regions yet assumes that the gender ideologies are stable in this time-period. The interdependence of respondents who were observed up to five times (on average, I retain 2.9 observations per respondent) is addressed by obtaining cluster robust standard errors. Robustness checks reveal similar results when limiting the estimation of gender pay gaps to single observations per respondent from 2018 (see Supplementary Table S2, Model 1), and I leverage multiple observations per respondent to highlight the robustness of the results with respect to unobserved heterogeneity in time-constant characteristics (see Section 5.2).

I restrict the sample to employed individuals between the ages of 18 and 64, excluding respondents in self-employment, military service, or apprenticeships. As the sample only consists of wage-earning employees, this raises concerns about varying selectivity of women in the labor force. A negative regional-level correlation of traditional gender ideologies and the employment rate of

\footnotetext{
${ }^{1}$ Employing administrative counties as contextual units does not alter the results substantially.
} 
women $(r=-0.384, p<0.001)$ indicates that women's labor force participation and hence their selection into the sample is associated with the regional gender ideologies. Simultaneously, a gender pay gap can disincentivize women to take up employment. Although previous research indicates that a selection bias is rather negligible for the estimation of gender pay gaps (Weichselbaumer and Winter-Ebmer, 2005; Olivetti and Petrongolo, 2008), I still find that greater regional female employment rates are weakly associated with smaller gender pay gaps $(r=0.149, p=0.017$, pay gaps are measured as the earning disadvantage for women). Thus, it is important to note that restricting the sample to wage-earning individuals may underestimate the impact of regional gender ideologies on gender pay gaps. After list-wise deletion of missing values, this leaves 51365 person-years of 17515 respondents in the analytic sample.

\subsection{Measuring Gender Pay Gaps and Wage-Determinants}

Gender pay gaps are estimated based on log hourly gross wages. Monthly gross wages were reported including potential wages based on extra hours, yet without irregular payments, such as bonus payments. ${ }^{2}$ These are divided by working hours (including extra hours) to obtain hourly wages, which are winsorized at the $1 \%$ level to adjust for implausible extreme values. Regressing the log of these hourly gross wages on respondents' gender yields regional gender pay gaps in multi-level models (see below).

Furthermore, four variables serve to investigate gender disparities in wagedeterminants in line with hypotheses H2a to H3b. The human capital endowment is assessed with two variables. Full-time employment is identified by at least 35 contractual working hours. An individual's labor market experience is based on retrospective reports of employment statuses over the whole life. Full-time and part-time employment are aggregated in one measure of labor market experience, weighting part-time employment with a factor of $0.5 .^{3}$ To measure vertical segregation, I employ information on supervisory positions that were reported biannually, corresponding to leading projects in highly qualified positions as well as to positions in top management. If individuals did not report any job changes since the last interview, information on supervisory positions was imputed for intermediate surveys. Horizontal segregation is captured by industry-specific shares of female employees. Branch of industries are surveyed and classified into a European scheme of industries (NACE), of which I obtain nine major categories. The share of female employees in a given labor market region for a given year is calculated for each category based on data of the Federal Employment Agency and matched for each respondent-year. ${ }^{4}$

\subsection{Estimating Regional Gender Ideologies}

The central independent variable is a region's gender ideology. I conceptualize regional gender ideologies as the average of individually held expectations about men's and women's behavior within a region, which in return depends on predictors of individual level gender beliefs. Accordingly, estimates of regional gender ideologies can be obtained in two steps (Moretti et al., 2019): first, an index of individual-level employment-related gender ideologies is generated, and second, accurate regional gender ideologies are obtained by Small Area Estimation procedures.

The individual expectations on gender roles were surveyed in 2018. I obtained an index based on responses (7-point scale) to three items: (1) "Children below the age of 6 suffer if their mother works", (2) "Children below the age of 3 suffer if their mother works", and (3) "It's best if the man and the woman work the same amount so they can share the responsibility for taking care of the family and household equally". While the first two items capture similar attitudes towards employment of mothers and are highly correlated $(r=0.78)$, the third item supplements opinions

\footnotetext{
${ }^{2}$ As research has shown that gender differences in bonus payments partly account for gender pay gaps (Collischon, 2019), this renders the obtained pay gaps as underestimated.

${ }^{3}$ Additionally, its squared term is included to account for diminishing returns.

${ }^{4}$ Commonly, segregation is measured across occupations, yet data on gender-specific prevalences of occupations is not available at the labor market at the region level. Nevertheless, industries still capture gendered patterns with construction being male-dominated and women being overrepresented in public administration and education. A correlation of 0.273 of the share of female employees across industries and one-digit ISCO-08 codes within the German Microcensus 2015 underlines this approach.
} 
towards the gendered allocation of responsibilities. ${ }^{5}$ Considering the above-mentioned sample restrictions, I construct an index by adding all valid survey responses to each item with equal weights $(N=25311, \alpha=0.60)$.

In a second step, I employ Small Area Estimation, which is a method for calculating statistics for domains with small sample sizes. The fact that respondents spread across all 257 labor market regions leaves few observations in some regions (see Supplementary Figure S1). This might lead to noisy estimates for sparsely sampled regions (Schunck, 2016) and might bias estimates when a region's respondents are not representative. Small Area Estimation "borrows strength" (Rao and Molina, 2015, XXIII) from domains with numerous observations (1) by considering information on the ratio of variation between and within regions and (2) by utilizing information on associations with auxiliary variables. Thereby, region-specific means of small domains with relatively high uncertainty and non-representative respondents are adjusted towards predictions based on auxiliary information. This does not only adjust otherwise noisy estimates for small sample domains but corresponds also to the reasoning that regional gender ideologies depend on compositional differences as well as on regional norm persistence. According to Section 2, the number of women, of working women, of college graduates, of individuals with a migration history, of Protestants and of Catholics as well as a region's age composition, its urbanity and an indicator for East German regions are incorporated in the Small Area Estimation. The region-level data are obtained from the Federal Statistical Office.

The model is estimated as a general linear mixed model (Supplementary Materials, Datta and Ghosh, 1991). ${ }^{6}$ All auxiliary predictors reveal significant associations in the expected direction (except for the urbanity indicator; see Supplementary Table S1) and uncertainty about regionallevel means is substantially reduced (Supplementary Figure S2). The final region-level estimates of gender ideologies are standardized across labor market regions, with higher values indicating more traditional ideologies.

\subsection{Controls}

Following previous research (Weichselbaumer and Winter-Ebmer, 2005), several control variables were included in the estimation of gender pay gaps to adjust for gender disparities in observable variables as well as structural differences across labor market regions. First, the respondents' age and marital status $(1=$ married $)$ as well as the number of children below age 18 in a household are included to account for demographic determinants of earnings. Additionally, controlling for the citizenship status ( $1=$ German citizenship) captures divergent labor market outcomes for natives and migrants as well as the varying dispersion of migrants across regions. Although gender differences in educational attainment have been declining and even reversed, I control for educational attainment in years, which is derived from the highest obtained degree in general and vocational education. Second, further characteristics of the job position include the number of years being employed with the current contract (tenure) and dummies for occupations based on ten major categories of the international ISCO-08-scheme. Third, regional differences in economic structures are captured by dummies for nine major industrial categories (based upon the European NACEclassification scheme) and by identifying individuals in the public sector as well as the size of the establishment they work in (Nisic, 2017). Although labor market regions are based on commuting patterns, some respondents might also commute to other labor market regions. Therefore, I adjust for commuting distances from the place of residence to the workplace in kilometers. Finally, I account for regional-level characteristics via the distinction between East- and West-Germany and an urbanity indicator distinguishing rural areas, agglomerated labor market regions, and urban centers (provided by the Federal Office for Building and Regional Planning). All models are adjusted for time-trends by including the survey year. Table A.1 in the Appendix ?? provides summary statistics for all incorporated variables.

\footnotetext{
${ }^{5}$ The third item is reversed. Weighting it twofold does not affect the results. All other surveyed items considered attitudes towards the institution of marriage, single parenthood, and same-sex couples and do not address gender explicitly.

${ }^{6}$ The model is implemented by employing the package hbsae in the statistical software R (Boonstra, 2015).
} 


\subsection{Multi-Level-Estimation of Regional Gender Gaps}

Random effects within multi-level models yield gender dissimilarities and their regional variation. The most parsimonious models obtain regional gender pay gaps by estimating an effect of the respondent's gender on their wages and simultaneously deriving region-level deviations of the overall gender-coefficient. In other words, individuals are nested within labor market regions and random slopes are used to evaluate the regional variation of gender pay gaps. The estimated model is represented by the following equation:

$$
y_{i r}=\alpha_{i r}+\left(\beta+\gamma_{r}\right) \text { gender }_{i r}+\delta \mathbf{X}_{i r}+\theta \mathbf{Z}_{r}+w_{r}+\epsilon_{i r},
$$

with $y_{i r}$ denoting the $\log$ of hourly gross wages for individual $i$ in labor market region $r$ and $\gamma_{r} \propto N\left(0, \sigma_{\gamma}\right)$ representing the region-level deviation of the overall gender-coefficient $(\beta)$. These coefficients are controlled for individual-level variables denoted by $\mathbf{X}_{i r}$ and the two regional-level variables denoted by $\mathbf{Z}_{r} . w_{r} \propto N\left(0, \sigma_{w}\right)$ depicts region-level random intercepts, and an independent individual-level error term is represented by $\epsilon_{i r}$. The multi-level estimation accounts for the nested structure and provides valid standard errors.

Adding individual-level wage-determinants partials out their gender inequalities, thus yielding adjusted gender pay gaps in $\beta$ and its regional variation in $\gamma_{r}$. Finally, cross-level interactions with region-level gender ideologies provide their moderating impact on the extent of regional gender disparities.

\section{Results}

Figure 2a depicts gender pay gaps across labor market regions, with darker shades indicating bigger gender pay gaps. The overall mean yields $\left(e^{-0.23}\right) 20.5$ percent lower hourly gross wages for women compared to men. A significant variation in the random slope $\left(\sigma_{\gamma}=0.112, p<0.001\right)$ reveals that the gender pay gap varies substantially across German labor market regions, ranging from a minimum of 43.7 percent to even wage premiums for women up to 12.4 percent. $^{7}$ In accordance with previous research, the regional variation of the extent that women are paid lessor even more - than men unfolds along prevalent spatial dimensions: East Germany displays a gender pay gap 10.9 percentage points lower (Diff. $=-0.116, p<0.001$ ), and the gender pay gap is lower in urban centers and agglomerated labor market regions than in rural regions (Diff. = $0.024, p=0.037$ ).

The Small Area estimates of gender ideologies yield a similar spatial pattern. A stark difference can be observed between East and West Germany, with regions of the former GDR being less traditional (depicted in brighter shades in Figure 2b). ${ }^{8}$ Beyond this previously highlighted divergence, which can be traced back to the institutional differences during the division (Lee et al., 2007; Zoch, 2021), Figure 2b indicates evidence of further substantial variation across German labor market regions. For instance, the politically more conservative southern federal States of Bavaria and Baden-Wuerttemberg yield more traditional gender ideologies than the rest of West Germany (Diff. $=0.103, p=0.089$ ). The urban Federal States of Hamburg, Bremen, and Berlin are regions with more liberal gender ideologies, and overall, rural labor market regions display more traditional gender ideologies than urban and agglomerated labor market regions (difference net off East-West disparity $=0.121, p=0.038$ ). According to the Small Area Estimation, the gender ideologies are less traditional in regions that are composed by a younger, less religious, and more educated population and with more women employed (Supplementary Table S1). An overall correspondence between the spatial distribution of gender pay gaps and gender ideologies results in a negative cross-region correlation $(r=-0.540, p<0.001)$, which supports hypothesis H1: regions with traditional gender ideologies display greater gender pay gaps.

\footnotetext{
${ }^{7}$ Wage premiums for women have been found before-especially in East Germany-and can be traced back to women in East German working more often in administrative jobs and bigger companies than East German men (Fuchs et al., 2019).

${ }^{8}$ This is not an artifact of including an indicator for East Germany as a predictor in the Small Area Estimation, since the same pattern is observed in the direct survey responses.
} 

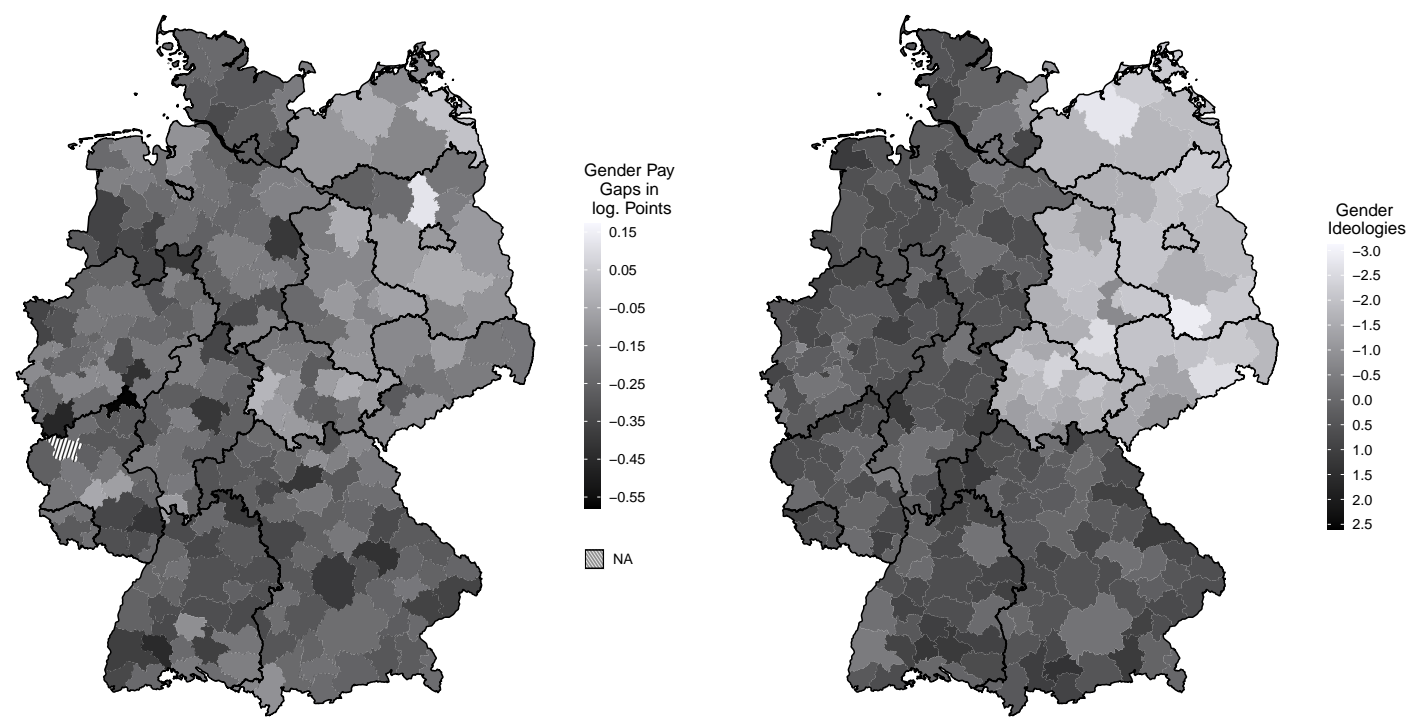

Figure 2: Region Level Gender Pay Gaps and Gender Ideologies. Source: SOEPv35; own estimation, regional pay gaps based on Model 1 of Table 2 .

\subsection{Unveiling Indirect and Direct Channels}

The theoretical framework presents indirect and direct channels underlying this association. The indirect channel presumes that gender ideologies predict gender disparities in wage-determinants, which then shape gender pay gaps. Therefore, Table 1 presents multi-level models for human capital-based and segregation-based indicators as dependent variables. A linear probability model (Model 1) indicates a likelihood 46.9 percentage points lower for women to work full-time. In accordance with $\mathrm{H} 2 \mathrm{a}$, regions in which traditional gender ideologies prevail encounter an even greater disparity in full-time employment, and this association accounts for 16 percent of the regional variation of gender disparities in full-time employment. Similarly, women accumulate on average 6.9 fewer years in the labor market compared to men, and this gap is amplified in more traditional labor market regions (Model 2 supporting H2b). Societal disapproval of mothers' employment and prescriptions of women's care-taking roles thus seems to push mothers into part-time employment or temporarily out of the labor market.

Turning to labor market segregation further supports that gender ideologies are predictive of gender disparities. Model 3 shows that the likelihood of holding a supervisory position is 15.9 percentage points lower for women in comparison to men. Corresponding to hypothesis H3a, a significant cross-level interaction indicates that the extent of this vertical segregation depends significantly on the labor market region's gender ideology. Only in the case of the horizontal segregation (Model 4) is hypothesis H3b not supported. While the share of women within industries varies across labor market regions, the lack of a significant cross-level interaction does not support that contextual gender ideologies moderate the sorting into different industries. ${ }^{9}$ This could be because the measurement of segregation across industries insufficiently address sex segregation (see Footnote 4) or alternatively, the measured gender attitudes capture beliefs of the incompatibility of motherhood and paid work rather than gender essentialist ideas about women's and men's specific skills. However, the overall results of Table 2 demonstrate that contextual gender ideologies account for gender disparities in several wage-determinants.

With this in mind, do gender disparities in wage-determinants account for the gender pay gap? Models 2, 3, and 4 in Table 2 respond to this question by incorporating the wage-determinants as independent variables in multi-level models of log hourly gross wages. Gender disparities in

\footnotetext{
${ }^{9}$ However, the coefficient of gender ideologies indicates that with each standard deviation towards more traditional gender ideologies, the share of female employees in industries decreases on average by 2 percentage points. Hence, traditional gender beliefs seem to hamper the labor force participation of women (see also Uunk and Lersch, 2019).
} 
Table 1: Multi-level Models Predicting Gender Disparities in Wage-Determinants by Gender Ideologies .

\begin{tabular}{lcccc}
\hline & \multicolumn{2}{c}{ Human Capital } & \multicolumn{2}{c}{ Segregation } \\
\hline & $(\mathbf{1})$ & $(\mathbf{2})$ & $\mathbf{( 3 )}$ & $\mathbf{( 4 )}$ \\
& Full-Time & Experience & Supervision & Female Share \\
\hline Gender $(1$ = female) $(\beta)$ & $-0.469^{* *}$ & $-6.913^{* *}$ & $-0.159^{* *}$ & $15.567^{* *}$ \\
& $(0.009)$ & $(0.124)$ & $(0.008)$ & $(0.403)^{* *}$ \\
Gender ideology & $0.037^{* *}$ & $0.908^{* *}$ & 0.005 & $-1.995^{* *}$ \\
& $(0.010)$ & $(0.149)$ & $(0.011)$ & $(0.713)$ \\
Gender $\times$ gender ideology & $-0.066^{* *}$ & $-1.256^{* *}$ & $-0.031^{* *}$ & 0.392 \\
& $(0.009)$ & $(0.120)$ & $(0.007)$ & $(0.419)^{* *}$ \\
sd(Gender) $\left(\sigma_{\gamma}\right)$ & $0.101^{* *}$ & $1.543^{* *}$ & $0.071^{* *}$ & $4.525^{* *}$ \\
& $(0.007)$ & $(0.118)$ & $(0.007)$ & $(0.347)$ \\
Socio-Demogr. controls ${ }^{*}$ & Yes & Yes & Yes & Yes \\
\hline Reduction in sd(Gender $)^{b}$ & 0.160 & 0.233 & 0.078 & 0.006 \\
AIC & 59587.92 & 324517.13 & 61603.52 & 448393.70 \\
Counties & 256 & 256 & 256 & 256 \\
Individuals & 17515 & 17515 & 17515 & \\
Person-Years & 51365 & 51365 & 51365 & 51365 \\
\hline
\end{tabular}

Source: SOEPv35; own estimation. Note: Levels of significance: ${ }^{*} p<0.05,{ }^{* *} p<0.01$. Robust standard errors shown in parentheses. Random intercepts not shown. ${ }^{a}$ Age, marital status, number of children in household below age 18, citizenship status, East-West distinction, urbanity-dummy-set, commuting distance and survey year. ${ }^{b}$ Relative reduction of $\sigma_{\gamma}$ when comparing models with and without the cross-level interaction.

the wage-determinants are partialled out of the gender coefficient $\beta$ and its random slope $\gamma_{r}$. Corresponding to previous evidence (Achatz et al., 2005; Minkus and Busch-Heizmann, 2018) accounting for gender disparities in full-time employment, working experience and other human capital variables in Model 2 cuts the gender pay gap in half since these are all positively associated with individual wages. Supervisory positions result in higher wages, and higher shares of female employees lead to lower wages for women and men in the industrial sector. This accounting for labor market segregation further reduces the gender pay gap by 10.8 percent $(-0.107 /-0.12)$ and gender disparities in all discussed wage-determinants together account for 53.5 percent $(-0.107 /-0.23)$ of the raw gender pay gap. Controlling for differences in branches of industries, company sizes and the size of the public sector across regions yields an adjusted gender pay gap of -0.094 log points in Model 4. Moreover, this adjusting does not only diminish the average gender pay gap, but also its regional variation by 49.2 percent. The resulting adjusted gender pay gaps reveal a less spatially structured distribution across all German regions and the employed gender inequalities in wagedeterminants completely account for the difference between East and West Germany (Figure A.1 in the Appendix ??; see also Fuchs et al., 2019). However, significant variation in the adjusted gender pay gaps persists $\left(\sigma_{\gamma}=0.055, p<0.001\right)$. 
Table 2: Multi-level Models of Log Hourly Gross Wages by Gender, Gender Ideologies, and Adjustment Variables.

\begin{tabular}{|c|c|c|c|c|c|c|c|c|}
\hline & \multicolumn{4}{|c|}{ Without Gender Ideology } & \multicolumn{4}{|c|}{ Cross-Level-Interaction } \\
\hline & $\begin{array}{c}(1) \\
\text { Raw Gap }\end{array}$ & $\begin{array}{c}\text { (2) } \\
\text { Human Cap. }\end{array}$ & $\begin{array}{c}(3) \\
\text { Segregation }\end{array}$ & $\begin{array}{c}(4) \\
\text { Adjusted }\end{array}$ & $\begin{array}{c}(5) \\
\text { Raw Gap }\end{array}$ & $\begin{array}{c}\text { (6) } \\
\text { Human Cap. }\end{array}$ & $\begin{array}{c}(7) \\
\text { Segregation }\end{array}$ & $\begin{array}{c}(8) \\
\text { Adjusted }\end{array}$ \\
\hline Gender $(1=$ female $)(\beta)$ & $\begin{array}{l}-0.230 \\
(0.009)\end{array}$ & $\begin{array}{l}-0.120^{* *} \\
(0.008)\end{array}$ & $\begin{array}{l}-0.107^{* *} \\
(0.008)\end{array}$ & $\begin{array}{l}-0.094^{* *} \\
(0.007)\end{array}$ & $\begin{array}{l}-0.234^{* *} \\
(0.008)\end{array}$ & $\begin{array}{l}-0.123^{* *} \\
(0.008)\end{array}$ & $\begin{array}{l}-0.110^{* *} \\
(0.008)\end{array}$ & $\begin{array}{l}-0.097^{* *} \\
(0.007)\end{array}$ \\
\hline Gender ideology & & & & & $\begin{array}{c}-0.019 \\
(0.017)\end{array}$ & $\begin{array}{c}0.005 \\
(0.013)\end{array}$ & $\begin{array}{c}0.003 \\
(0.011)\end{array}$ & $\begin{array}{c}-0.001 \\
(0.010)\end{array}$ \\
\hline Gender $\times$ gender ideology & & & & & $\begin{array}{l}-0.074^{* *} \\
(0.008)\end{array}$ & $\begin{array}{l}-0.035^{* *} \\
(0.007)\end{array}$ & $\begin{array}{l}-0.027^{* *} \\
(0.006)\end{array}$ & $\begin{array}{l}-0.025^{* *} \\
(0.006)\end{array}$ \\
\hline Education in years & & $\begin{array}{l}0.085^{* *} \\
(0.001)\end{array}$ & $\begin{array}{l}0.050^{* *} \\
(0.002)\end{array}$ & $\begin{array}{l}0.046^{* *} \\
(0.002)\end{array}$ & & $\begin{array}{l}0.085^{* *} \\
(0.001)\end{array}$ & $\begin{array}{l}0.050^{* *} \\
(0.002)\end{array}$ & $\begin{array}{l}0.046^{* *} \\
(0.002)\end{array}$ \\
\hline Full time employment? $(1=$ yes $)$ & & $\begin{array}{l}0.059^{* *} \\
(0.007)\end{array}$ & $\begin{array}{l}0.025^{* *} \\
(0.006)\end{array}$ & $\begin{array}{l}0.010 \\
(0.006)\end{array}$ & & $\begin{array}{l}0.059^{* *} \\
(0.007)\end{array}$ & $\begin{array}{l}0.024^{* *} \\
(0.006)\end{array}$ & $\begin{array}{c}0.010 \\
(0.006)\end{array}$ \\
\hline Working experience & & $\begin{array}{l}0.030^{* *} \\
(0.001)\end{array}$ & $\begin{array}{l}0.026^{* *} \\
(0.001)\end{array}$ & $\begin{array}{l}0.023^{* *} \\
(0.001)\end{array}$ & & $\begin{array}{l}0.030^{* *} \\
(0.001)\end{array}$ & $\begin{array}{l}0.026^{* *} \\
(0.001)\end{array}$ & $\begin{array}{l}0.023 \\
(0.001)\end{array}$ \\
\hline Supervising position? $(1=$ yes $)$ & & & $\begin{array}{l}0.074^{* *} \\
(0.006)\end{array}$ & $\begin{array}{l}0.088^{* *} \\
(0.006)\end{array}$ & & & $\begin{array}{l}0.074^{* *} \\
(0.006)\end{array}$ & $\begin{array}{l}0.088^{* *} \\
(0.006)\end{array}$ \\
\hline$\%$ of female employees in industry & & & $\begin{array}{c}-0.001^{* *} \\
(0.000)\end{array}$ & $\begin{array}{c}-0.001 \\
(0.001)\end{array}$ & & & $\begin{array}{c}-0.001^{* *} \\
(0.000)\end{array}$ & $\begin{array}{c}-0.001 \\
(0.001)\end{array}$ \\
\hline $\operatorname{sd}($ Gender $)\left(\sigma_{\gamma}\right)$ & $\begin{array}{l}0.112 \\
(0.010)\end{array}$ & $\begin{array}{l}0.075^{* *} \\
(0.008)\end{array}$ & $\begin{array}{l}0.058^{* *} \\
(0.007)\end{array}$ & $\begin{array}{l}0.055^{* *} \\
(0.007)\end{array}$ & $\begin{array}{l}0.082^{* *} \\
(0.009)\end{array}$ & $\begin{array}{l}0.066^{* *} \\
(0.008)\end{array}$ & $\begin{array}{l}0.051 \\
(0.007)\end{array}$ & $\begin{array}{l}0.049 \\
(0.006)\end{array}$ \\
\hline Socio-demogr. controls ${ }^{a}$ & Yes & Yes & Yes & Yes & Yes & Yes & Yes & Yes \\
\hline Human capital controls $b$ & & Yes & Yes & Yes & & Yes & Yes & Yes \\
\hline Segregation controls ${ }^{c}$ & & & Yes & Yes & & & Yes & Yes \\
\hline Sectorial controls ${ }^{d}$ & & & & Yes & & & & Yes \\
\hline Reduction in sd(Gender) ${ }^{e}$ & & 0.326 & 0.478 & 0.506 & 0.271 & 0.409 & 0.541 & 0.567 \\
\hline AIC & 68253.79 & 49870.48 & 43779.99 & 39815.53 & 68587.71 & 49841.82 & 43757.07 & 39793.18 \\
\hline Counties & 256 & 256 & 256 & 256 & 256 & 256 & 256 & 256 \\
\hline Individuals & 17515 & 17515 & 17515 & 17515 & 17515 & 17515 & 17515 & 17515 \\
\hline Person-years & 51365 & 51365 & 51365 & 51365 & 51365 & 51365 & 51365 & 51365 \\
\hline
\end{tabular}

Source: SOEPv35; own estimation. Note: Levels of significance: ${ }^{*} p<0.05,{ }^{* *} p<0.01$. Robust standard errors shown in parentheses. Random intercepts not shown. Human Capital model includes additionally the squared term of working experience. ${ }^{a}$ Age, marital status, number of children in household below age 18 , citizenship status, East-West distinction, urbanity-dummy-set, commuting distance, and survey year. ${ }^{b}$ Tenure and squared term of working experience. ${ }^{c}$ Ten occupational dummies (ISCO). ${ }^{d}$ Nine industrial dummies (NACE), public sector, and company size. ${ }^{e}$ Relative reduction of $\sigma_{\gamma}$ for the model comparison with the baseline model (1). 
Since region-level gender ideologies were shown to be predictive of gender disparities in wagedeterminants and since the latter account for the extent of the gender pay gap, Models 5 to 8 indicate how region-level gender ideologies shape regional gender pay gaps indirectly and even directly. The significant cross-level interaction of gender ideologies and an individual's gender in Model 5 again supports hypothesis $\mathrm{H} 1$ of traditional gender ideologies enhancing raw gender pay gaps. While in regions with gender ideologies one standard deviation above its mean, the gender pay gap is $0.309 \log$ points, this shrinks to wages only $-0.160 \log$ points lower for women in regions that are one standard deviation less traditional than the average (Figure 3). As Table 1 indicates that gender ideologies predict gender disparities in the human capital variables, the cross-level interaction diminishes when adjusting for these in Model 6 of Table 2. Similarly, a further decrease can be observed when controlling for labor market segregation in Model 7 and for structural differences across regions in Model 8. While gender ideologies accounted for 27.1 percent of the cross-region variation of the raw gender pay gap in Model 5, the additional explanatory power of the cross-level interaction reduces starkly when comparing the reduction in the random slope between Model 4 and Model 8. Thus, the association of regional gender ideologies and regional pay gaps is primarily indirect and works through inducing gender disparities in wage-determinants.

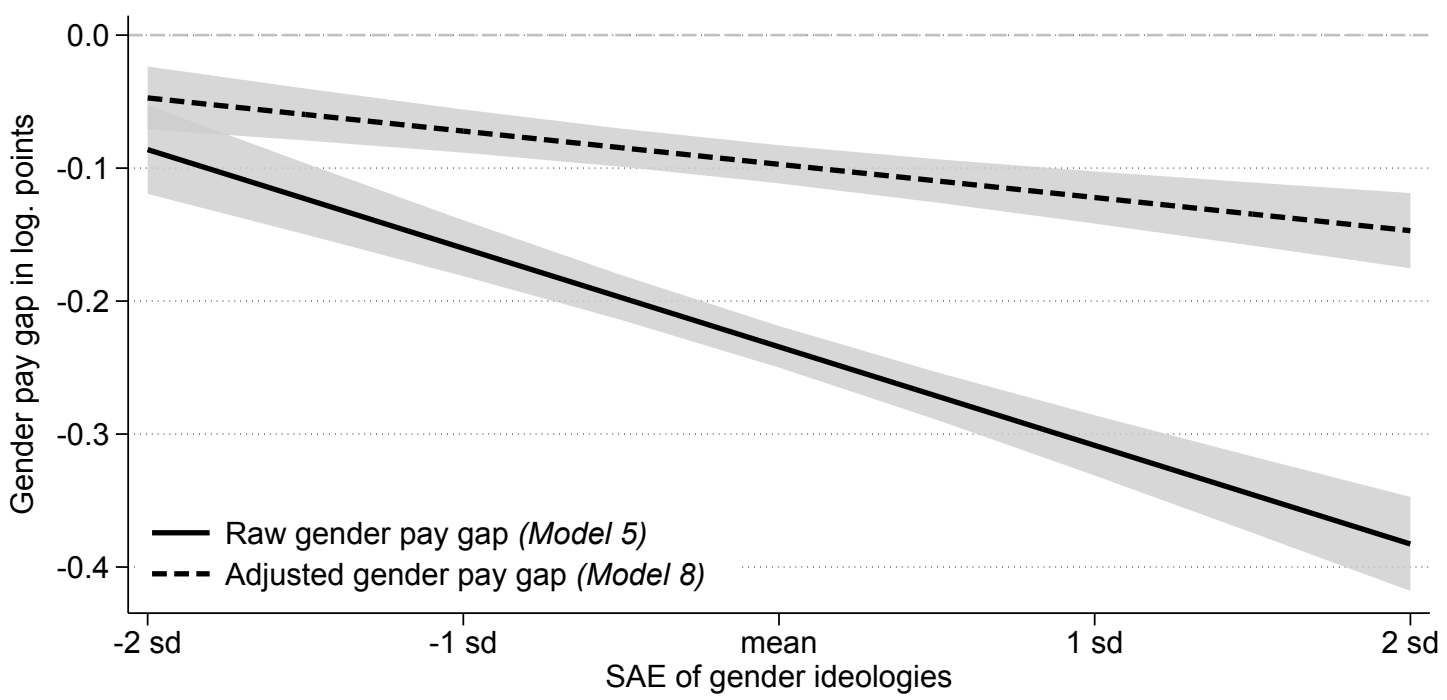

Figure 3: Predicted Gender Pay Gap by Gender Ideologies. Source: SOEP v35, own estimation, based on Table 2. Note: Shaded areas mark 95 percent confidence intervals.

Yet even after accounting for a whole list of adjustment variables, the remaining regional variation of adjusted gender pay gaps can be attributed to region-level gender ideologies. The significant predictive power of the cross-level interaction in Model 8 supports hypothesis H4: each standard deviation towards more traditional gender ideologies increases the adjusted gender pay gap by 2.5 percentage points. This relationship is visualized in Figure 3, which also indicates the indirect effect of gender ideologies through intermediate gender disparities in wage-determinants via the difference between the association of gender ideologies with raw gender pay gaps (solid line) and with adjusted gender wage gaps (dashed line). Especially in regions with traditional gender ideologies, the prevalent raw gender pay gaps are substantially reduced when adjusting for the mediation of gender inequalities in human capital and of labor market segregation. The remaining slope of gender ideologies is weaker, yet it indicates that societal gender ideologies are also directly associated with the extent that women earn lower wages than men. As discussed before, this might be based on gender ideologies shaping wage negotiation behavior (Leibbrandt and List, 2015), perceptions of fair wages (Lang and Groß, 2020), discriminatory behavior, or gender differences in further omitted wage-determinants. 


\subsection{Robustness Checks}

The conceptualization of regional gender ideologies mentions the internalization of norms and their institutionalization as two potential mechanisms of how gender ideologies affect labor market outcomes in a region (see Section 2). To assess these, I conducted two supplementary analyses: I introduced the individual level gender beliefs surveyed in 2018 as well as an indicator of public child care provision (share of children under the age of 6 in public childcare), as this is one of the main employment-related policies that varies across labor market regions. Each indicator interacted with the respondent's gender, and, corresponding to the idea of both variables reflecting mechanisms for the association of regional gender ideologies and gender pay gaps, accounting for them diminishes the cross-level interaction of regional gender ideologies in comparison to the cross-level interaction in Model 8 of Table 2 (cf. Supplementary Table S2). However, significant associations remain even after the adjustment; thus, other mechanisms such as behavioral adherence regardless of individually held gender beliefs as well as differential treatment by others likely apply as well.

Furthermore, several robustness checks were performed to check whether the findings are sensitive to model or sample specifications (Supplementary Table S3). First, the support for hypothesis $\mathrm{H} 4$ seems to be independent of the measure of gender ideologies and its adjustment by the Small Area Estimation procedures. Raw regional averages of the gender ideology index yield a similar cross-level interaction. Second, regions with very few observations do not affect the results, as limiting the analysis to regions with at least 30 observations of wage-earning individuals leads to the same conclusions. Third, some individuals were surveyed multiple times, which allows adjusting for unobserved heterogeneity in time-constant characteristics by incorporating individual-specific averages of all independent variables (Mundlak, 1978). While the null hypothesis that coefficients of the individual-level averages are zero has to be rejected - indicating that unobserved heterogeneity might confound previous coefficients - the support for hypothesis H4 remains stable. Fourth, since spatially close regions potentially affect each other via spill-over effects, a spatial lag of gender ideologies based on the inverse distance matrix of all regions is included (Halleck Vega and Elhorst, 2015). However, accounting for spatial dependence does not affect the overall conclusions. Finally, previous research has indicated regional variation in gender pay gaps between East and West Germany (Minkus and Busch-Heizmann, 2018) and by urbanity (Nisic, 2017). While by adjusting for urbanity and East-West indicators in Model 8 accounted for differences in average wages, it neglected how these regional characteristics moderate the gender pay gap. In response, I calculated separated models for each part of Germany and included cross-level interactions by urbanity and respondents' gender to model potential differences in the gender slope across both dimensions. The cross-level interaction for the regional gender ideologies is virtually unchanged for West Germany, and regional gender ideologies are still significantly predictive of adjusted gender pay gaps across West German labor market regions. However, the significant regional variation in gender pay gaps cannot be traced back to gender ideologies within East Germany.

\section{Conclusion}

This study provides novel evidence on how contextual gender ideologies can account for regional variations in gender pay gaps within Germany. It was shown that contextual gender ideologies vary substantially across German labor market regions, and this within-country variation has been exploited to predict gender pay gaps. The results reveal that contextual gender ideologies can account not only for regional gender pay gaps in general but also for intermediate gender disparities in wage-determinants. Additionally, gender ideologies were shown to be predictive of adjusted gender pay gaps.

These findings have two important implications for future research. First, going beyond previously invoked differences in gender ideologies between East- and West-Germany (Lee et al., 2007; Zoch, 2021), the results reveal that further heterogeneity across regional labor markets exists based on compositional differences and varying degrees of norm persistence. Future studies can exploit such regional variation to assess how contextual gender ideologies prompt gendered outcomes while bypassing potential confounding of national idiosyncrasies in cross-national studies (cf. Uunk and Lersch, 2019). Other subnational demarcations, such as religious denominations or educational attainment, may constitute important boundaries of gendered expectations as well; however, they 
predominantly shape behavior through socialization and individual compliance of its direct members. In contrast, regional contexts emphasize the importance of gender ideologies not only based on individual beliefs, but additionally through effects of differential treatment by others (such as employers and costumers) as well as through shaping region-specific institutions.

Second, applying this to gender disparities in wage-determinants and gender pay gaps in Germany underlines cross-national evidence on the importance of contextual gender ideologies for prompting gender inequalities in the labor market (cf. Fortin 2005, 2015, Charles, 2003. My analysis of the indirect path emphasizes that gender disparities in wage-determinants, such as labor market experience, working hours, or supervisory positions, do not necessarily explain gender pay gaps; rather they need to be explained as well (Lips, 2013), and regional gender ideologies are highlighted as one of their potential causes. Moreover, the remaining direct association between gender ideologies and pay gaps endorses concerns that cultural contexts likely maintain gender pay gaps via discrimination or gender-specific wage-negotiation behavior even when policies aiming at equipping women and men with equal labor market endowments would succeed (Aisenbrey and Brückner, 2008). While policies such as the proliferation of parental leave or public child care can counteract traditional gender ideologies (Gangl and Ziefle, 2015; Zoch and Schober, 2018), the findings imply that gender pay gaps likely persist as long as cultural contexts prescribe divergent behavior for each gender or female-dominated occupations are culturally devalued even when women and men have equal opportunities (Busch, 2013a). This holds especially as norms do not always align with institutional environments and contextual gender ideologies can inhibit the impact of policies (Peters et al., 2020; Kümmerling and Postels, 2020). While my study provides robust within-country evidence on how regional gender ideologies shape gender inequalities in the labor market, further understanding is thus required of how they interplay with policies for achieving gender equity.

This study can only serve as an exploratory step in this direction. It suffers from limitations that future research should address. For instance, the associations shown of regional gender ideologies and gender gaps in earnings and labor market relevant traits were only correlational and not causal. Unequal labor market outcomes also likely affect gendered expectations by exposing individuals to gender-stereotype-affirming disparities between women and men, which can be "learned" and internalized as gender beliefs (Brooks and Bolzendahl, 2004). Such a feedback mechanism renders the obtained association between regional gender ideologies and (adjusted) gender pay gaps as overestimated. Yet, it unlikely invalidates the results by accounting for the whole observed association, because the review of previous research clearly indicates that a causal effect of gender ideologies on gendered outcomes exists. Nevertheless, future research could exploit longitudinal variation to assess the extent of reversed causality of gender inequalities in the labor market perpetuating regional gender ideologies. Additionally, longitudinal data would allow utilizing variation between those who moved between labor market regions and those who stayed continuously in the same region. This could help to assess to what extent moving individuals adopt preexisting gender inequalities and regional gender ideologies or rather self-select into regions that match one's own gender ideologies. For instance, Grunow and Müller (2012) highlight how mothers who moved from East to West Germany partly adjust their length of child-bearing related employment breaks to prevailing norms in West Germany, independently of self-selection.

Additionally, my analysis builds on an aggregate measure of perceived role incompatibility of motherhood and paid work as well as equal allocation of responsibilities in heterosexual couples. It was especially predictive for gender disparities in indicators of labor force participation. As the sample only consists of wage-earning employees, this raises concerns about varying selectivity of women into the labor force. Uunk and Lersch (2019) show for the United Kingdom that in regions with traditional gender ideologies, women are less likely to be employed. I found a similar association for Germany, which might have introduced endogeneity between the selection into the analytic sample and regional gender ideologies, which would render the estimated association of regional gender ideologies and gender pay gaps as underestimated. In contrast, the obtained measure was not predictive of regional variation in industry-specific gender compositions. Future research thus could also survey supplementary items on gender essentialist ideas of women and men having divergent inherent abilities. This would allow examining how gender ideologies affect horizontal labor market segregation more directly and corresponds to growing criticism on unidimensional measurements of gender ideologies (Charles and Grusky, 2004; Grunow et al., 2018). 
Finally, the employed survey items on the incompatibility of motherhood and paid work are restricted to mothers, neglecting the role of fathers in combining employment and domestic chores, taking care of children, or stepping back from full-time employment. Thus, improved measures should also incorporate expectations about fathers to assess their influence on the gender pay gap (Walter, 2018). 


\section{References}

Achatz, J., Gartner, H., Glück, T., 2005. Bonus oder Bias? KZfSS Kölner Zeitschrift für Soziologie und Sozialpsychologie 57, 466-493. doi:10.1007/s11577-005-0185-6.

Aisenbrey, S., Brückner, H., 2008. Occupational Aspirations and the Gender Gap in Wages. European Sociological Review 24, 633-649. doi:10.1093/esr/jcn024.

Arpino, B., Esping-Andersen, G., Pessin, L., 2015. How Do Changes in Gender Role Attitudes Towards Female Employment Influence Fertility? A Macro-Level Analysis. European Sociological Review 31, 370-382. doi:10. 1093/esr/jcv002.

Auspurg, K., Hinz, T., Sauer, C., 2017. Why Should Women Get Less? Evidence on the Gender Pay Gap from Multifactorial Survey Experiments. American Sociological Review 82, 179-210. doi:10.1177/0003122416683393.

Azmat, G., Petrongolo, B., 2014. Gender and the Labor Market: What Have We Learned from Field and Lab Experiments? IZA Discussion Paper, Nr. 8135.

Bertrand, M., Kamenica, E., Pan, J., 2015. Gender Identity and Relative Income within Households. The Quarterly Journal of Economics 130, 571-614. doi:10.1093/qje/qjv001.

Blau, F.D., Brinton, M.C., Grusky, D.B., 2006. The Declining Significance of Gender?, in: Blau, F.D., Brinton, M.C., Grusky, D.B. (Eds.), The Declining Significance of Gender?. Russell Sage Foundation, New York, N.Y., pp. 3-34.

Blau, F.D., Kahn, L.M., 2017. The Gender Wage Gap: Extent, Trends, and Explanations. Journal of Economic Literature 55, 789-865. doi:10.1257/jel.20160995.

Boll, C., Rossen, A., Wolf, A., 2017. The EU Gender Earnings Gap: Job Segregation and Working Time as Driving Factors. Jahrbücher für Nationalökonomie und Statistik 237, 407-452. doi:10.1515/jbnst-2017-0100.

Bolzendahl, C.I., Myers, D.J., 2004. Feminist Attitudes and Support for Gender Equality: Opinion Change in Women and Men, 1974-1998. Social Forces 83, 759-790. doi:10.1353/sof .2005.0005.

Boonstra, H.J., 2015. Package 'hbsae'. R package version 1.0. URL: https://cran.r-project.org/web/packages/ hbsae/index.html.

Bozzano, M., 2017. On the historical roots of women's empowerment across Italian provinces: religion or family culture? European Journal of Political Economy 49, 24-46. doi:10.1016/j.ejpoleco.2016.12.002.

Brooks, C., Bolzendahl, C.I., 2004. The transformation of US gender role attitudes: Cohort replacement, socialstructural change, and ideological learning. Social Science Research 33, 106-133. doi:10.1016/S0049-089X(03) 00041-3.

Busch, A., 2013a. Der Einfluss der beruflichen Geschlechtersegregation auf den Gender Pay Gap. KZfSS Kölner Zeitschrift für Soziologie und Sozialpsychologie 65, 301-338. doi:10.1007/s11577-013-0201-1.

Busch, A., 2013b. Die berufliche Geschlechtersegregation in Deutschland: Ursachen, Reproduktion, Folgen. Springer VS, Wiesbaden.

Charles, M., 2003. Deciphering Sex Segregation. Vertical and Horizontal Inequalities in Ten National Labor Markets. Acta Sociologica 46, 267-287. doi:10.1177/0001699303464001.

Charles, M., Grusky, D.B., 2004. Occupational Ghettos: The Worldwide Segregation of Women and Men. Studies in social inequality, Stanford University Press, Stanford, CA.

Chatillon, A., Charles, M., Bradley, K., 2018. Gender Ideologies, in: Risman, B.J., Froyum, C.M., Scarborough, W.J. (Eds.), Handbook of the Sociology of Gender. Springer International Publishing, Cham, pp. $217-226$.

Chung, H., Meuleman, B., 2017. European parents' attitudes towards public childcare provision: the role of current provisions, interests and ideologies. European Societies 19, 49-68. doi:10.1080/14616696.2016.1235218.

Collischon, M., 2019. Is There a Glass Ceiling over Germany? German Economic Review 20, e329-e359. doi:10. 1111 /geer. 12168.

Cooper, J., Croyle, R.T., 1984. Attitudes and Attitude Change. Annual Review of Psychology 35, 395-426. doi:10.1146/annurev.ps.35.020184.002143.

Correll, S.J., 2004. Constraints into Preferences: Gender, Status, and Emerging Career Aspirations. American Sociological Review 69, 93-113.

Datta, G.S., Ghosh, M., 1991. Bayesian Prediction in Linear Models: Applications to Small Area Estimation. The Annals of Statistics 19, 1748-1770.

Davis, S.N., Greenstein, T.N., 2009. Gender Ideology: Components, Predictors, and Consequences. Annual Review of Sociology 35, 87-105. doi:10.1146/annurev-soc-070308-115920.

Eagly, A.H., Karau, S.J., 2002. Role congruity theory of prejudice toward female leaders. Psychological Review 109, 573-598. doi:10.1037//0033-295X.109.3.573.

England, P., 1992. Comparable Worth: Theories and Evidence. Social institutions and social change. 1st ed. ed., Taylor and Francis, Somerset. URL: https://ebookcentral.proquest.com/lib/gbv/detail.action?docID= 4906378.

Evans, A., 2016. The Decline of the Male Breadwinner and Persistence of the Female Carer: Exposure, Interests, and Micro-Macro Interactions. Annals of the American Association of Geographers 106, 1135-1151. doi:10. 1080/24694452.2016.1184557.

Federal Statistical Office, 2019. Verdienstunterschied zwischen Frauen und Männern 2018 unverändert bei $21 \%$. URL: pressemitteilung No. 098, https:www.destatis.deDEPressePressemitteilungen201903PD19_098_621.html.

Fernández, R., 2007. Women, Work, and Culture. Journal of the European Economic Association 5, 305-332. doi:10.1162/jeea.2007.5.2-3.305.

Finke, C., Dumpert, F., Beck, M., 2017. Verdienstunterschiede zwischen Männern und Frauen: Eine Ursachenanalyse auf Grundlage der Verdienststrukturerhebung 2014. Wirtschaft und Statistik , 43-62.

Fortin, N.M., 2005. Gender Role Attitudes and the Labour-market Outcomes of Women across OECD Countries. Oxford Review of Economic Policy 21, 416-438. doi:10.1093/oxrep/gri024.

Fortin, N.M., 2015. Gender Role Attitudes and Women's Labor Market Participation: Opting-Out, AIDS, and the 
Persistent Appeal of Housewifery. Annals of Economics and Statistics, 379-401doi:10.15609/annaeconstat2009. 117-118.379.

Fuchs, M., Rossen, A., Weyh, A., Wydra-Somaggio, G., 2019. Why do women earn more than men in some regions? Explaining regional differences in the gender pay gap in Germany. IAB-Discussion Paper 11-2019.

Fuwa, M., 2004. Macro-Level Gender Inequality and the Division of Household Labor in 22 Countries. American Sociological Review 69, 751-767. doi:10.1177/000312240406900601.

Gangl, M., Ziefle, A., 2015. The Making of a Good Woman: Extended Parental Leave Entitlements and Mothers' Work Commitment in Germany. American Journal of Sociology 121, 511-563. doi:10.1086/682419.

Gilbert, D.T., 1998. Ordinary personology, in: Gilbert, D.T., Fiske, S.T., Lindzey, G. (Eds.), Handbook of social psychology. McGraw-Hill, Boston, MA, pp. 89-150.

Giuliano, P., 2018. Gender, in: Averett, S.L., Argys, L.M., Hoffman, S.D., Giuliano, P. (Eds.), The Oxford Handbook of Women and the Economy. Oxford University Press, pp. 644-672. doi:10.1093/oxfordhb/9780190628963.013. 29.

Goebel, J., Grabka, M.M., Liebig, S., Kroh, M., Richter, D., Schröder, C., Schupp, J., $2019 . \quad$ The German Socio-Economic Panel (SOEP). Jahrbücher für Nationalökonomie und Statistik 239, 345-360. doi:10.1515/ jbnst-2018-0022.

Goldin, C., 2014. A Grand Gender Convergence: Its Last Chapter. American Economic Review 104, $1091-1119$. doi:10.1257/aer.104.4.1091.

Grunow, D., Begall, K., Buchler, S., 2018. Gender Ideologies in Europe: A Multidimensional Framework. Journal of Marriage and Family 80, 42-60. doi:10.1111/jomf.12453.

Grunow, D., Müller, D., 2012. Kulturelle und strukturelle Faktoren bei der Rückkehr in den Beruf: ostdeutsche, westdeutsche und ost-west-mobile Mütter im Vergleich. Institut für Arbeitsmarkt- und Berufsforschung. IABDiscussion Paper 02/2012.

Halleck Vega, S., Elhorst, J.P., 2015. The SLX Model. Journal of Regional Science 55, 339-363. doi:10.1111/jors. 12188.

Hirsch, B., König, M., Möller, J., 2013. Is There a Gap in the Gap? Regional Differences in the Gender Pay Gap. Scottish Journal of Political Economy 60, 412-439. doi:10.1111/sjpe.12017.

Holst, E., Wrohlich, K., 2018. Spitzengremien großer Unternehmen: Geschlechterquote für Aufsichtsräte greift, in Vorständen herrscht beinahe Stillstand. DIW Wochenbericht 2018, 3-17.

Horne, C., Mollborn, S., 2020. Norms: An Integrated Framework. Annual Review of Sociology 46, 467-487. doi:10.1146/annurev-soc-121919-054658.

Judge, T.A., Livingston, B.A., 2008. Is the gap more than gender? A longitudinal analysis of gender, gender role orientation, and earnings. The Journal of applied psychology 93, 994-1012. doi:10.1037/0021-9010.93.5.994.

Kaufman, G., White, D., 2015. What Makes a "Good Job"? Gender Role Attitudes and Job Preferences in Sweden. Gender Issues 32, 279-294. doi:10.1007/s12147-015-9145-2.

Kleven, H., Landais, C., Søgaard, J.E., 2019. Children and Gender Inequality: Evidence from Denmark. American Economic Journal: Applied Economics 11, 181-209. doi:10.1257/app.20180010.

Kümmerling, A., Postels, D., 2020. Ist die Geschlechterrolleneinstellung entscheidend? Die Wirkung länderspezifischer Geschlechterkulturen auf die Erwerbsarbeitszeiten von Frauen. KZfSS Kölner Zeitschrift für Soziologie und Sozialpsychologie 72, 193-224. doi:10.1007/s11577-020-00698-9.

Lalive, R., Stutzer, A., 2010. Approval of equal rights and gender differences in well-being. Journal of Population Economics 23, 933-962. doi:10.1007/s00148-009-0257-4.

Lang, V., Groß, M., 2020. The just gender pay gap in Germany revisited: The male breadwinner model and regional differences in gender-specific role ascriptions. Research in Social Stratification and Mobility 65, 100473. doi:10.1016/j.rssm.2020.100473.

Lee, K.S., Alwin, D.F., Tufis, P.A., 2007. Beliefs about Women's Labour in the Reunified Germany, 19912004. European Sociological Review 23, 487-503. doi:10.1093/esr/jcm015.

Leibbrandt, A., List, J.A., 2015. Do Women Avoid Salary Negotiations? Evidence from a Large-Scale Natural Field Experiment. Management Science 61, 2016-2024. doi:10.1287/mnsc. 2014.1994.

Levanon, A., Grusky, D.B., 2016. The Persistence of Extreme Gender Segregation in the Twenty-first Century. American Journal of Sociology 122, 573-619.

Lips, H.M., 2013. The Gender Pay Gap: Challenging the Rationalizations. Perceived Equity, Discrimination, and the Limits of Human Capital Models. Sex Roles 68, 169-185. doi:10.1007/s11199-012-0165-z.

Minkus, L., Busch-Heizmann, A., 2018. Gender Wage Inequalities Between Historical Heritage and Structural Adjustments: A German-German Comparison Over Time. Social Politics: International Studies in Gender, State \& Society 57, 1-31. doi:10.1093/sp/jxy032.

Moretti, A., Shlomo, N., Sakshaug, J.W., 2019. Small Area Estimation of Latent Economic Well-being. Sociological Methods \& Research 62,1-34. doi:10.1177/0049124119826160.

Mundlak, Y., 1978. On the Pooling of Times Series and Cross Section Data. Econometrica 46, 69-85. doi:10.2307/ 1913646.

Nisic, N., 2017. Smaller Differences in Bigger Cities? Assessing the Regional Dimension of the Gender Wage Gap. European Sociological Review 33, 292-304. doi:10.1093/esr/jcx037.

Olivetti, C., Petrongolo, B., 2008. Unequal Pay or Unequal Employment? A Cross-Country Analysis of Gender Gaps. Journal of Labor Economics 26, 621-654. doi:10.1086/589458.

Perales, F., Lersch, P.M., Baxter, J., 2019. Birth cohort, ageing and gender ideology: Lessons from British panel data. Social Science Research 79, 85-100. doi:10.1016/j.ssresearch.2018.11.003.

Pessin, L., 2018. Changing Gender Norms and Marriage Dynamics in the United States. Journal of Marriage and Family 80, 25-41. doi:10.1111/jomf .12444.

Peters, E., Drobe, J., Abendroth, A., 2020. Gleichheit durch Gleichstellungsmaßnahmen? KZfSS Kölner Zeitschrift für Soziologie und Sozialpsychologie 72, 225-263. doi:10.1007/s11577-020-00695-y. 
Polavieja, J.G., 2015. Capturing Culture. American Sociological Review 80, 166-191. doi:10.1177/ 0003122414562600

Quenzel, G., Hurrelmann, K., 2010. Geschlecht und Schulerfolg: Ein soziales Stratifikationsmuster kehrt sich um. KZfSS Kölner Zeitschrift für Soziologie und Sozialpsychologie 62, 61-91. doi:10.1007/s11577-010-0091-4.

Rao, J.N.K., Molina, I., 2015. Small area estimation. Wiley series in survey methodology. second edition ed., John Wiley \& Sons Inc, Hoboken New Jersey. doi:10.1002/9781118735855.

Reuben, E., Sapienza, P., Zingales, L., 2014. How stereotypes impair women's careers in science. Proceedings of the National Academy of Sciences of the United States of America 111, 4403-4408. doi:10.1073/pnas.1314788111.

Rice, L., Barth, J.M., 2017. A Tale of Two Gender Roles: The Effects of Implicit and Explicit Gender Role Traditionalism and Occupational Stereotype on Hiring Decisions. Gender Issues 34, 86-102. doi:10.1007/ s12147-016-9175-4.

Rudman, L.A., Phelan, J.E., 2010. The Effect of Priming Gender Roles on Women's Implicit Gender Beliefs and Career Aspirations. Social Psychology 41, 192-202. doi:10.1027/1864-9335/a000027.

Salikutluk, Z., Heyne, S., 2017. Do Gender Roles and Norms Affect Performance in Maths? The Impact of Adolescents' and their Peers' Gender Conceptions on Maths Grades. European Sociological Review 33, 368-381. doi:10.1093/esr/jcx049.

Scarborough, W.J., Risman, B.J., 2017. Changes in the gender structure: Inequality at the individual, interactional, and macro dimensions. Sociology Compass 11, 1-16.

Scarborough, W.J., Sin, R., 2020. Gendered Places: The Dimensions of Local Gender Norms across the United States. Gender \& Society 34, 705-735. doi:10.1177/0891243220948220.

Schunck, R., 2016. Cluster Size and Aggregated Level 2 Variables in Multilevel Models. A Cautionary Note: methods, data, analyses, Vol 10, No 1 (2016). methods, data, analyses 10, 97-108. doi:10.12758/MDA.2016.005.

Sprengholz, M., Wieber, A., Holst, E., 2020. Gender identity and wives' labor market outcomes in West and East Germany between 1983 and 2016. Socio-Economic Review doi:10.1093/ser/mwaa048.

Steinhauer, A., 2018. Working Moms, Childlessness, and Female Identity. LIEPP Working Paper, Nr. 79.

Taylor, T., Turgeon, B., Buck, A., Bloch, K., Church, J., 2019. Spatial Variation in U.S. Labor Markets and Workplace Gender Segregation: 1980-2005. Sociological Inquiry 89, 703-726. doi:10.1111/soin.12279.

Thébaud, S., Pedulla, D.S., 2016. Masculinity and the Stalled Revolution. Gender \& Society 30, 590-617. doi:10. $1177 / 0891243216649946$.

Trappe, H., Pollmann-Schult, M., Schmitt, C., 2015. The Rise and Decline of the Male Breadwinner Model: Institutional Underpinnings and Future Expectations. European Sociological Review 31, 230-242. doi:10.1093/ esr/jcv015.

Uunk, W., Lersch, P.M., 2019. The Effect of Regional Gender-Role Attitudes on Female Labour Supply: A Longitudinal Test Using the BHPS, 1991-2007. European Sociological Review 115, 669-683. doi:10.1093/esr/jcz026.

Walter, J.G., 2018. Measures of gender role attitudes under revision: The example of the German General Social Survey. Social Science Research 72, 170-182. doi:10.1016/j.ssresearch.2018.02.009.

Weichselbaumer, D., Winter-Ebmer, R., 2005. A Meta-Analysis of the International Gender Wage Gap. Journal of Economic Surveys 19, 479-511. doi:10.1111/j.0950-0804.2005.00256.x.

West, C., Zimmerman, D.H., 1987. Doing Gender. Gender \& Society 1, 125-151. doi:10.1177/0891243287001002002.

Zoch, G., 2021. Thirty Years after the Fall of the Berlin Wall-Do East and West Germans Still Differ in Their Attitudes to Female Employment and the Division of Housework? European Sociological Review doi:10.1093/ esr/jcab002.

Zoch, G., Schober, P.S., 2018. Public Child-Care Expansion and Changing Gender Ideologies of Parents in Germany. Journal of Marriage and Family 80, 1020-1039. doi:10.1111/jomf.12486. 


\section{Appendix}

Table A.1: Descriptive Statistics of Analytic Sample

\begin{tabular}{|c|c|c|c|c|}
\hline & Mean & SD & Min & $\operatorname{Max}$ \\
\hline \multicolumn{5}{|l|}{ Dependent variable } \\
\hline Hourly gross earnings & 16.74 & 9.01 & 1.07 & 55.4 \\
\hline Log(hourly gross earnings) & 2.67 & 0.57 & .0674 & 4.01 \\
\hline \multicolumn{5}{|l|}{ Gender variables } \\
\hline Gender $(1=$ female $)$ & 0.52 & & 0 & 1 \\
\hline Index of gender ideology & 0.00 & 1.00 & -1.62 & 2.49 \\
\hline $\mathrm{SAE}$ of gender ideologies & -0.28 & 1.03 & -2.95 & 2.05 \\
\hline \multicolumn{5}{|l|}{ Human capital } \\
\hline Education in years & 12.72 & 2.75 & 7 & 18 \\
\hline Working experience & 17.33 & 11.13 & 0 & 64.5 \\
\hline Firm tenure & 11.55 & 10.38 & 0 & 50.6 \\
\hline Full time employment? $(1=$ yes $)$ & 0.57 & & 0 & 1 \\
\hline \multicolumn{5}{|l|}{ Segregation } \\
\hline Supervising position? ( $1=$ yes $)$ & 0.28 & & 0 & 1 \\
\hline$\%$ of female employees in industry & 49.21 & 20.81 & 0 & 83.9 \\
\hline \multicolumn{5}{|l|}{ Occupation: } \\
\hline Legislators, officials and managers & 0.05 & & 0 & 1 \\
\hline Professionals & 0.21 & & 0 & 1 \\
\hline Technicians and ass. professionals & 0.25 & & 0 & 1 \\
\hline Clerks & 0.11 & & 0 & 1 \\
\hline Service and sales workers & 0.13 & & 0 & 1 \\
\hline Agricultural workers & 0.01 & & 0 & 1 \\
\hline Crafts & 0.11 & & 0 & 1 \\
\hline Machine operators & 0.07 & & 0 & 1 \\
\hline Unskilled occupations & 0.07 & & 0 & 1 \\
\hline \multicolumn{5}{|l|}{ Controls } \\
\hline Works in public sector $?(1=$ yes $)$ & 0.27 & & 0 & 1 \\
\hline \multicolumn{5}{|l|}{ Industrial sector: } \\
\hline Construction & 0.04 & & 0 & 1 \\
\hline Finance, insurance & 0.04 & & 0 & 1 \\
\hline Professional service & 0.07 & & 0 & 1 \\
\hline Real estate & 0.01 & & 0 & 1 \\
\hline Retail trade, transportation, accomodation & 0.19 & & 0 & 1 \\
\hline Information, communication & 0.04 & & 0 & 1 \\
\hline Art, entertainment & 0.03 & & 0 & 1 \\
\hline Agriculture & 0.01 & & 0 & 1 \\
\hline Industry & 0.25 & & 0 & 1 \\
\hline Public adminstration, education, defence & 0.32 & & 0 & 1 \\
\hline \multicolumn{5}{|l|}{ Establishment size: } \\
\hline Less than 20 & 0.21 & & 0 & 1 \\
\hline 20 or more, less than 200 & 0.27 & & 0 & 1 \\
\hline 200 or more, less than 2000 & 0.23 & & 0 & 1 \\
\hline More than 2000 & 0.30 & & 0 & 1 \\
\hline Commuting distance in $\mathrm{km}$ & 17.27 & 32.57 & 0 & 999 \\
\hline Marital status ( $1=$ married $)$ & 0.65 & & 0 & 1 \\
\hline Nr. of children younger than 18 & 0.88 & 1.09 & 0 & 10 \\
\hline German citizenship? ( 1 = yes) & 0.90 & & 0 & 1 \\
\hline Age & 44.48 & 10.96 & 18 & 65 \\
\hline Region ( 1 = East Germany) & 0.19 & & 0 & 1 \\
\hline \multicolumn{5}{|l|}{ Urbanity: } \\
\hline Urban Center & 0.67 & & 0 & 1 \\
\hline Agglomerated labor market & 0.16 & & 0 & 1 \\
\hline Rural area & 0.17 & & 0 & 1 \\
\hline Observations & 53306 & & & \\
\hline Regions & 256 & & & \\
\hline
\end{tabular}

Source: SOEPv35; own calculation 


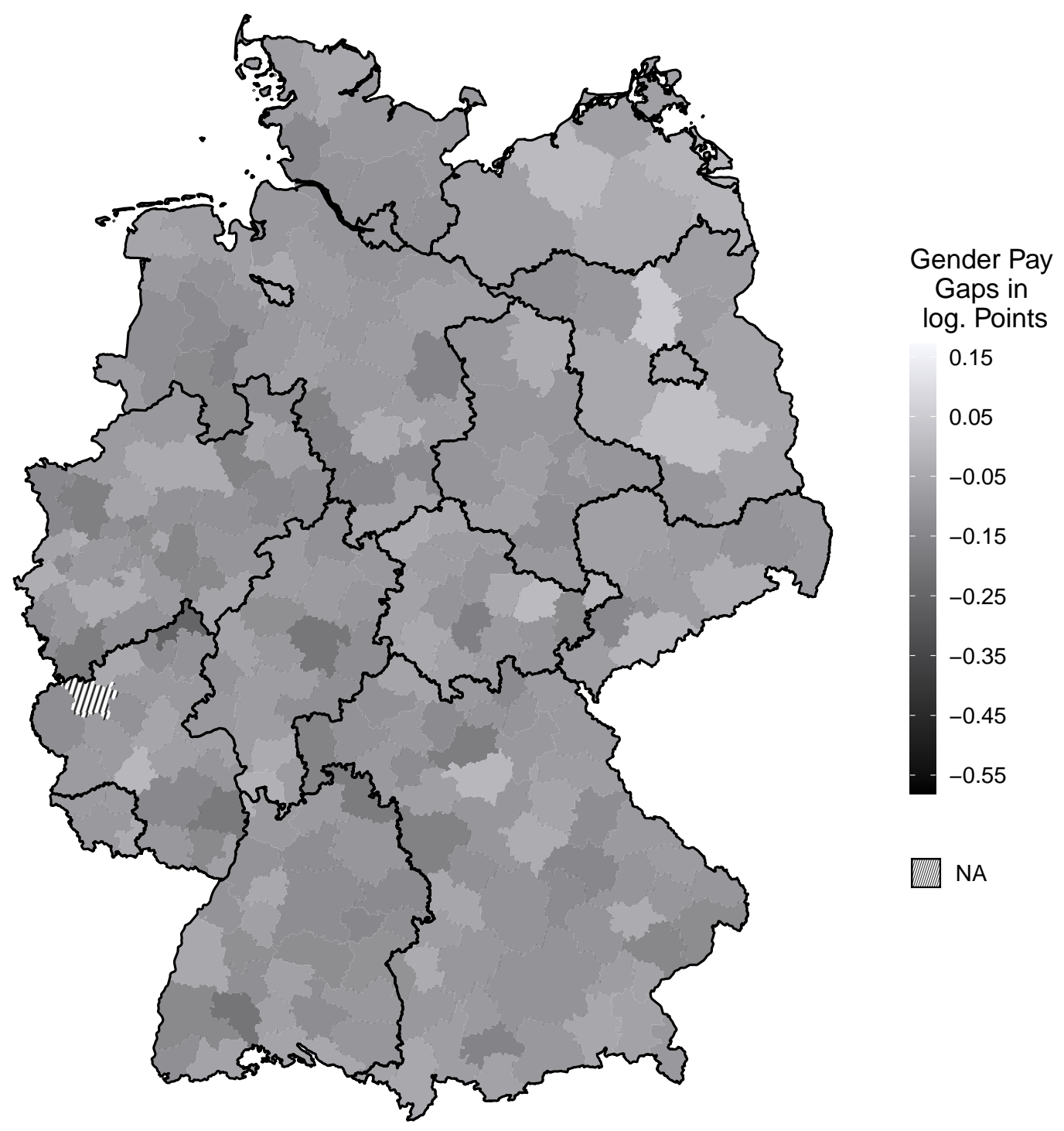

Source: SOEPv35; own estimation based on $\beta$ and random slopes of Model 4 of Table 2 


\section{Supplementary Material for Can Regional Gender Ideologies Account for Variation of Gender Pay Gaps? The Case of Germany}

\section{Small Area Estimation}

Let $\mathbf{D}_{p}$ be an $N \times R$ matrix indicating the membership of population unit $i$ belonging to region $r$ and let $\mathbf{f}_{p}$ denote a vector of population values for gender ideologies of $N$ observations. The population mean of factor scores of gender ideologies $\bar{f}_{d}$ is predicted for each region based on knowledge about $\mathbf{D}_{p}$, on $\mathbf{X}_{p}$ as an $N \times k$ matrix for $k$ auxiliary variables at the individual level and about $\mathbf{Z}$ as a vector of the region-level predictors. Therefore, each matrix is partitioned into observed values and non-sampled values, the latter marked by the subscript $j$ :

$$
\mathbf{f}_{p}=\left[\begin{array}{l}
\mathbf{f} \\
\mathbf{f}_{j}
\end{array}\right]=\left[\begin{array}{l}
\mathbf{X} \\
\mathbf{X}_{j}
\end{array}\right] \boldsymbol{\beta}+\mathbf{Z} \gamma+\left[\begin{array}{l}
\mathbf{D} \\
\mathbf{D}_{j}
\end{array}\right] \mathbf{v}+\left[\begin{array}{l}
\mathbf{e} \\
\mathbf{e}_{j}
\end{array}\right]
$$

where the error matrix $\mathbf{e}$ and random intercepts for region-averages $\mathbf{v}$ are independent, with $\mathbf{e} \sim N\left(0, \sigma^{2}\right)$ and $\mathbf{v} \sim N\left(0, \sigma^{2} \boldsymbol{\lambda}\right) . \quad \boldsymbol{\lambda}$ represents the ratio of within-region variance and total variance. Thereby, synthetic gender ideologies $\mathbf{f}_{j}$ for non-sampled units will be estimated by the auxiliary information and their associations $\boldsymbol{\beta}$ and $\gamma$ as well as by the region's random intercept $v_{d}$ (based on the ratio of global and its region-level variance $\lambda_{r}$ ). The lower the number of sampled units within a region $n_{r}$ in comparison to its actual population size $N_{d}$, the more weight is given to the synthetic gender ideologies, imputing also reliable values for potentially non-sampled regions. Hierarchical Bayes estimates for the gender ideology index were obtained using uninformative priors on $\boldsymbol{\beta}, \gamma, \sigma^{2}$ and $\boldsymbol{\lambda}$ (coefficients are shown in Table S1). Finally, a vector of region-level adjusted means of gender ideologies is predictors to reflect the region-specific gender ideologies. 
Table S1: Small Area Estimation Coefficients and Modelfit

\begin{tabular}{|c|c|}
\hline & Coefficient \\
\hline Gender ( 1 = female $)$ & $\begin{array}{l}-0.267^{* *} \\
(0.027)\end{array}$ \\
\hline \multicolumn{2}{|l|}{ Age (Ref.: 35-44): } \\
\hline $18-24$ & $\begin{array}{c}-0.055 \\
(0.056)\end{array}$ \\
\hline $25-34$ & $\begin{array}{r}-0.027 \\
(0.039)\end{array}$ \\
\hline $45-54$ & $\begin{array}{l}0.131^{* *} \\
(0.032)\end{array}$ \\
\hline $55-64$ & $\begin{array}{l}0.220^{* *} \\
(0.039)\end{array}$ \\
\hline 65 and above & $\begin{array}{l}0.263^{* *} \\
(0.040)\end{array}$ \\
\hline \multicolumn{2}{|l|}{ Urbanity (Ref.: Densed labor market region): } \\
\hline Rural labor market region & $\begin{array}{c}0.043 \\
(0.053)\end{array}$ \\
\hline Metropolitan labor market region & $\begin{array}{c}0.041 \\
(0.047)\end{array}$ \\
\hline College Degree? (1 = yes $)$ & $\begin{array}{c}-0.494^{* *} \\
(0.023)\end{array}$ \\
\hline Female Employment? (1 = yes) & $\begin{array}{l}-0.202^{* *} \\
(0.031)\end{array}$ \\
\hline Migrationbackground? (1 = yes) & $\begin{array}{l}0.425^{* *} \\
(0.026)\end{array}$ \\
\hline \multicolumn{2}{|l|}{ Religious denomination (Ref.: None or others) } \\
\hline Catholic & $\begin{array}{l}0.147^{* *} \\
(0.027)\end{array}$ \\
\hline Ev. Protestant & $\begin{array}{l}0.072^{* *} \\
(0.026)\end{array}$ \\
\hline Subpart of Germany ( $1=$ East $)$ & $\begin{array}{c}-0.939^{* *} \\
(0.048)\end{array}$ \\
\hline Intercept & $\begin{array}{l}3.030^{* *} \\
(0.056)\end{array}$ \\
\hline Within variance $\left(\hat{\sigma}_{e}^{2}\right)$ & $\begin{array}{c}1.797^{* *} \\
(0.019)\end{array}$ \\
\hline Variance ratio $(\lambda)$ & 0.025 \\
\hline$R^{2}$ (individual level) & 0.176 \\
\hline $\mathrm{AIC}$ & 62315 \\
\hline Nr. of individuals & 18244 \\
\hline Nr. of regions & 257 \\
\hline
\end{tabular}

Source: SOEP v35 and auxiliary information by Destatis, own estimation

Note: Levels of significance: ${ }^{*} p<0.05,{ }^{* *} p<0.01$. Standard errors shown in parentheses. 


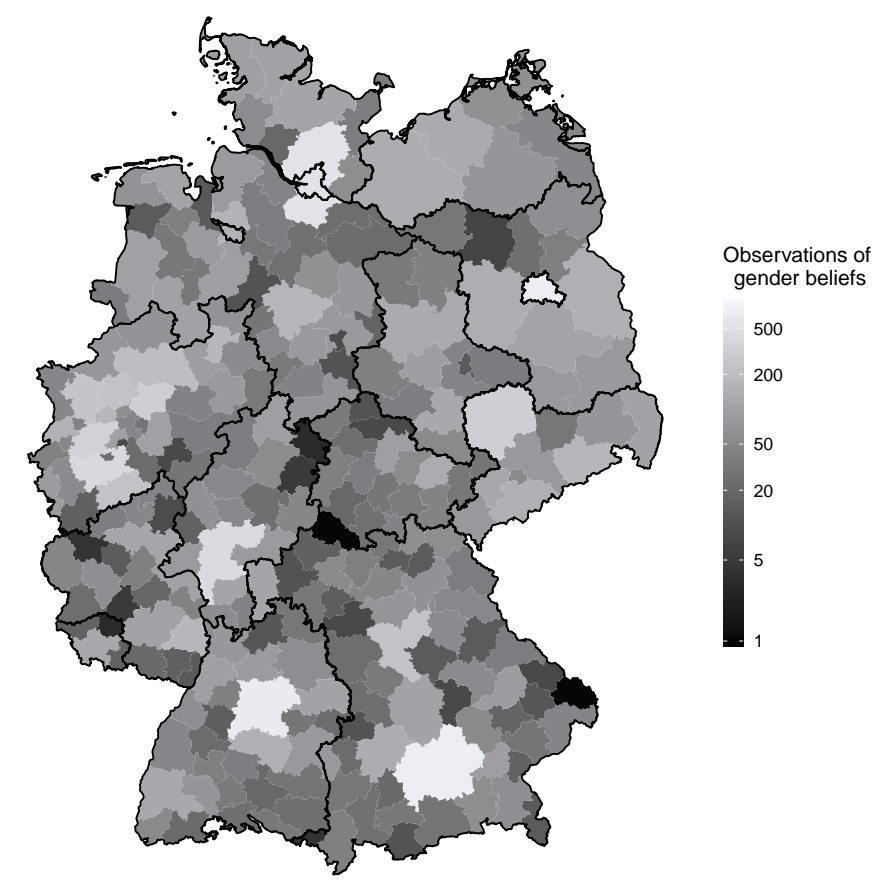

Source: SOEPv35; own estimation

Note: Number of observations lies between 1 and more than 500 in agglomerated regions (Stuttgart in the southwest, Munich in south-east, Berlin, and Hamburg)

Figure S2: Coefficient of Variation of Aggregated Gender Ideology Index and Small Area Estimates by Region's Sample Size

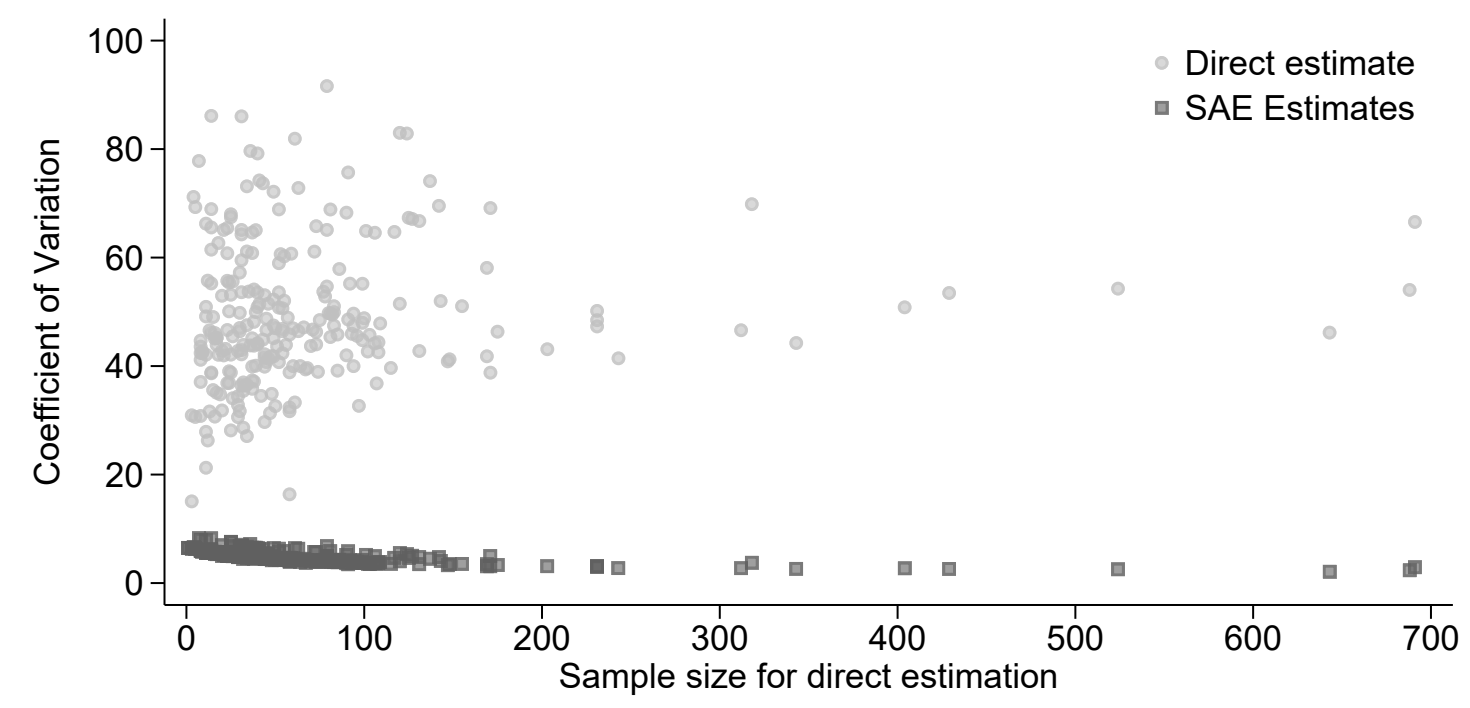

SOEP v35, own estimation 
Table S2: Multi-level Models of Log Hourly Gross Wages by Gender, Gender Ideologies and two Mediating Variables

\begin{tabular}{|c|c|c|}
\hline & $\begin{array}{c}\text { (1) } \\
\text { Individual level index }\end{array}$ & $\begin{array}{c}(2) \\
\text { Regional level childcare }\end{array}$ \\
\hline Gender $(1=$ female $)(\beta)$ & $\begin{array}{l}-0.102^{* *} \\
(0.010)\end{array}$ & $\begin{array}{r}-0.114 \\
(0.073)\end{array}$ \\
\hline Gender ideology & $\begin{array}{c}0.005 \\
(0.010)\end{array}$ & $\begin{array}{r}-0.006 \\
(0.011)\end{array}$ \\
\hline Gender $\times$ gender ideology & $\begin{array}{r}-0.014^{*} \\
(0.007)\end{array}$ & $\begin{array}{r}-0.023^{*} \\
(0.010)\end{array}$ \\
\hline Individual level gender beliefs index & $\begin{array}{c}-0.001 \\
(0.005)\end{array}$ & \\
\hline Gender $\times$ individual level index & $\begin{array}{l}-0.032^{* *} \\
(0.007)\end{array}$ & \\
\hline Share of children ; 6 in childcare & & $\begin{array}{r}-0.245^{+} \\
(0.139)\end{array}$ \\
\hline Gender $\times$ share in childcare & & $\begin{array}{c}0.028 \\
(0.119)\end{array}$ \\
\hline $\operatorname{sd}($ Gender $)\left(\sigma_{\gamma}\right)$ & $\begin{array}{c}0.000 \\
(0.000)\end{array}$ & $\begin{array}{l}0.048^{* *} \\
(0.006)\end{array}$ \\
\hline Socio-demogr. controls ${ }^{c}$ & Yes & Yes \\
\hline Human capital controls ${ }^{c}$ & Yes & Yes \\
\hline Segregation $^{c}$ & Yes & Yes \\
\hline Sectorial controls ${ }^{c}$ & Yes & Yes \\
\hline AIC & 5378.31 & 39793.46 \\
\hline Counties & 255 & 256 \\
\hline Individuals & 9013 & 17515 \\
\hline Pearson-Years & 9013 & 51365 \\
\hline
\end{tabular}

Source: SOEP v35, own estimation

Note: Levels of significance: ${ }^{+} p<0.1,{ }^{*} p<0.05,{ }^{* *} p<0.01$. Standard errors shown in parentheses. Random intercepts not shown.

${ }^{a}$ Controls are equivalent to Model 8 in Table 2. 
Table S3: Robustness Checks of Multi-Level Models of Log Hourly Gross Wages by Gender and Gender Ideologies

\begin{tabular}{|c|c|c|c|c|c|c|}
\hline & \multirow[b]{2}{*}{$\begin{array}{l}(1) \\
\text { Index } \mathrm{w} / \mathrm{o} \mathrm{SAE}\end{array}$} & \multirow[b]{2}{*}{$\stackrel{(2)}{n_{c} \geq 30}$} & \multirow[b]{2}{*}{$\begin{array}{c}(3) \\
\text { Mundlak approach }\end{array}$} & \multirow[b]{2}{*}{$\begin{array}{c}(4) \\
\text { Spatial dep. }\end{array}$} & \multicolumn{2}{|c|}{ Within subparts } \\
\hline & & & & & $\begin{array}{l}(5) \\
\text { West }\end{array}$ & $\begin{array}{l}(6) \\
\text { East }\end{array}$ \\
\hline Gender $(1=$ female $)(\beta)$ & $-0.096^{* *}$ & $\frac{1}{-0.098^{* *}}$ & $-0.076^{* *}$ & $-0.096^{* *}$ & $-0.093^{* *}$ & $\begin{array}{l}\text { Ldst } \\
-0.078\end{array}$ \\
\hline & $(0.007)$ & $(0.007)$ & $(0.009)$ & $(0.008)$ & $(0.013)$ & $(0.049)$ \\
\hline Gender ideology & 0.006 & -0.001 & 0.000 & -0.006 & 0.001 & -0.014 \\
\hline Gender $\times$ gender ideology & $-0.025^{* *}$ & $\begin{array}{l}(0.010)^{*} \\
-0.025^{* *}\end{array}$ & $\begin{array}{l}(0.011)^{* *} \\
-0.021^{*}\end{array}$ & $\begin{array}{c}(0.010) \\
-0.018^{*}\end{array}$ & $\begin{array}{c}(0.013) \\
-0.028^{*}\end{array}$ & $\begin{array}{l}(0.019) \\
0.008\end{array}$ \\
\hline Spatial lag of gender ideology & $(0.006)$ & $(0.006)$ & $(0.007)$ & $\begin{array}{c}(0.008) \\
0.028^{*} \\
(0.013)\end{array}$ & $(0.012)$ & $(0.025)$ \\
\hline Gender $\times$ spatial lag of gender ideology & & & & $\begin{array}{r}-0.014 \\
(0.012)\end{array}$ & & \\
\hline $\operatorname{sd}($ Gender $)\left(\sigma_{\gamma}\right)$ & $0.049^{* *}$ & $0.047^{* *}$ & $0.045^{* *}$ & $0.049^{* *}$ & $0.046^{* *}$ & $0.053^{* *}$ \\
\hline Socio-demogr. controls ${ }^{c}$ & $(0.006)$ & $(0.006)$ & $\left(\begin{array}{l}0.007) \\
\text { Yes }\end{array}\right.$ & $(0.006)$ & $(0.008)$ & $(0.012)$ \\
\hline Human capital controls ${ }^{c}$ & Yes & Yes & Yes & Yes & Yes & Yes \\
\hline Segregation ${ }^{c}$ & Yes & Yes & Yes & Yes & Yes & Yes \\
\hline Sectorial controls ${ }^{c}$ & Yes & Yes & Yes & Yes & Yes & Yes \\
\hline $\begin{array}{l}\text { Individual level means of covariates } \\
\text { Cross-level interaction }\end{array}$ & & & Yes & & Yes & \\
\hline $\begin{array}{l}\text { Cross-level interaction with urbanity } \\
\text { AIC }\end{array}$ & 39795.26 & 39649.98 & 19643.75 & 39791.43 & 32475.00 & $\begin{array}{l}\text { Yes } \\
6945.74\end{array}$ \\
\hline Counties & 256 & 242 & 256 & 256 & 203 & 53 \\
\hline Person-Years & 51365 & 51121 & 51365 & 51365 & 41820 & 9545 \\
\hline
\end{tabular}

Source: SOEP v35, own estimation

Note:Levels of significance: ${ }^{+} p<0.1,{ }^{*} p<0.05,{ }^{* *} p<0.01$. Standard errors shown in parentheses. Random intercepts not shown.

${ }^{a}$ Individual-level means of indicators on gender attitudes and aggregated within regions without SAE adjustment.

${ }^{6}$ Builds upon inverse distance matrix of centroids of all regions.

${ }^{c}$ Controls are equivalent to Model 8 in Table 2. 